\title{
Nanotechnology-based drug delivery systems for the treatment of Alzheimer's disease
}

\author{
This article was published in the following Dove Press journal: \\ International Journal of Nanomedicine \\ 4 August 2015 \\ Number of times this article has been viewed
}

\section{Bruno Fonseca-Santos \\ Maria Palmira Daflon \\ Gremião \\ Marlus Chorilli}

Department of Drugs and Medicines, School of Pharmaceutical Sciences, São Paulo State University (UNESP), Araraquara, São Paulo, Brazil
Correspondence: Marlus Chorilli Department of Drugs and Medicines, School of Pharmaceutical Sciences, São Paulo State University, Rodovia Araraquara-Jaú, km I, Araraquara, São Paulo, Brazil

Email chorilli@fcfar.unesp.br

\begin{abstract}
Alzheimer's disease is a neurological disorder that results in cognitive and behavioral impairment. Conventional treatment strategies, such as acetylcholinesterase inhibitor drugs, often fail due to their poor solubility, lower bioavailability, and ineffective ability to cross the blood-brain barrier. Nanotechnological treatment methods, which involve the design, characterization, production, and application of nanoscale drug delivery systems, have been employed to optimize therapeutics. These nanotechnologies include polymeric nanoparticles, solid lipid nanoparticles, nanostructured lipid carriers, microemulsion, nanoemulsion, and liquid crystals. Each of these are promising tools for the delivery of therapeutic devices to the brain via various routes of administration, particularly the intranasal route. The objective of this study is to present a systematic review of nanotechnology-based drug delivery systems for the treatment of Alzheimer's disease.
\end{abstract}

Keywords: Alzheimer's disease, polymeric nanoparticles, solid lipid nanocarriers, microemulsions, liquid crystals, targeted delivery, nose-to-brain

\section{Introduction}

Alzheimer's disease (AD) is an acquired disorder of cognitive and behavioral impairment that is an incurable disease with a long and progressive course. ${ }^{1}$ In $\mathrm{AD}$, plaques develop in the hippocampus, ${ }^{2}$ a structure deep in the brain that helps to encode memories, and in other areas of the cerebral cortex that are used in thinking and decision making.

In the US, an estimated 5.2 million people of all ages have AD. This disease is the sixth leading cause of death in the US overall and the fifth leading cause of death for those aged 65 years and older. Deaths from Alzheimer's increased by $68 \%$ between 2000 and 2010, while deaths from human immunodeficiency virus (HIV), stroke, and heart disease decreased by $42 \%, 23 \%$, and $16 \%$, respectively. By 2050 , the number of people aged 65 years and older with $\mathrm{AD}$ may nearly triple from 5 million to a projected 13.8 million unless medical breakthroughs are made to prevent, retard, or stop the disease progression. ${ }^{3}$

There are several limitations associated with present therapy, and the intranasal strategy seems to be a promising route for delivery of drugs to brain. ${ }^{4}$ Currently approved drugs for treating the cognitive impairments in AD are based on neurotransmitter or enzyme modulation. ${ }^{4}$ Acetylcholinesterase (AChE) inhibitors are associated with gastrointestinal adverse effects like nausea and vomiting that most commonly lead to discontinuation of treatment. 5,6 Tacrine has a short half-life and needs four administrations per day. ${ }^{7}$ In addition, patients who used the drug required periodic blood monitoring due to hepatotoxicity. ${ }^{8}$ Also, galantamine and rivastigmine exhibit a half-life of 7 and 2 hours, respectively. The use of memantine can cause adverse 
Table I Summary of the pharmacokinetic parameters of the cholinesterase inhibitors and memantine

\begin{tabular}{llllll}
\hline Drug & Bioavailability (\%) & $\mathbf{t}_{\text {max }}(\mathbf{h})$ & Protein binding (\%) & Half-life (h) & Hepatic metabolism \\
\hline Tacrine $^{7}$ & $17-37$ & $0.5-3$ & 75 & $1.3-7.0$ & CYPIA2, CYP2D6 \\
Donepezil $^{7}$ & 100 & $3-5$ & 96 & $60-90$ & CYP2D6, CYP3A4 \\
Rivastigmine $^{7}$ & 40 & $0.8-1.7$ & 40 & 2 & Non-hepatic \\
Galantamine $^{7}$ & $85-100$ & $0.5-1.5$ & 18 & $5-7$ & CYP2D6, CYP3A4 \\
Memantine $^{10,11}$ & 100 & $3-7$ & 45 & $60-80$ & \\
\hline
\end{tabular}

Abbreviations: CYP, cytochrome P450; $\mathrm{t}_{\max }$, time to maximum serum concentration; $h$, hours.

effects as dizziness, confusion, constipation, and vomiting. ${ }^{9}$ A summary of pharmacokinetic parameters of drugs used in AD are shown in Table 1.

Therapy failure frequently occurs due to the unfavorable pharmacokinetics and pharmacodynamics of drugs. ${ }^{12}$ Pharmacotherapy failure is the result of inadequate physical chemistry of drugs (such as hydrophobicity), unfavorable absorption by biological membranes, unfavorable pharmacokinetic parameters (such as intense and plasma metabolism), instability of drugs (oxidation, hydrolysis, or photolysis), and toxicity to tissues (hepatotoxicity, neurotoxicity, or kidney toxicity). ${ }^{12-14}$ The use of drugs in nanoplatforms or nanodevices results in the enhancement of their pharmacokinetics and pharmacodynamics, as well as they can to exhibit minimal toxicity. ${ }^{15,16}$ On the one hand, an essential aspect in nanomedicine development is the controlled release of drugs into disease sites. ${ }^{12,14,17,18}$

The effectiveness of a treatment can be increased by incorporating nanotechnology-based drug delivery systems. ${ }^{19,20}$ Some of these new platforms, which aim to improve the bioavailability, pharmacokinetics, and pharmacodynamics of drugs while reducing their side effects, are shown in Table 2 .

\section{AD pathophysiology}

AD is histopathologically characterized by a massive synaptic loss and neuronal death observed in the brain regions responsible for cognitive functions, including the cerebral cortex, hippocampus, entorhinal cortex, and ventral striatum. ${ }^{55}$ In the brain parenchyma of patients with $\mathrm{AD}$, fibrillar amyloid deposits located on the walls of blood vessels are associated with a variety of different types of senile plaques, the accumulation of abnormal tau protein filaments, and the subsequent formation of neurofibrillary tangles, neuronal and synaptic loss, glial cell activation, and inflammation. ${ }^{55}$ Two hypotheses have been proposed for the etiology and pathophysiology of AD: the first hypothesis pertains to amyloidal cascade neurodegeneration, whereas the second pertains to the dysfunction of the cholinergic system: tau aggregation, metal-mediated toxicity, and inflammation.
According to the amyloidal cascade neurodegeneration hypothesis, AD begins with the proteolytic cleavage of the amyloid precursor protein (APP) and results in the production, aggregation, and deposition of $\beta$-amyloid $(A \beta)$ and amyloid plaques (Figure 1A). ${ }^{56,57}$ The deposition of $A \beta$ is increased in patients with AD when there are mutations in APP and presenilin (PS). ${ }^{56,58}$ An increase in metal-mediated neurotoxicity is also associated with the deposition of $A \beta .{ }^{59}$ When the concentration of $A \beta$ is high, insoluble amyloid fibers are formed in the brain. These fibers may be complexed with zinc and copper, thereby aggravating the neuronal toxicity. ${ }^{60}$ Copper has shown the ability to increase $A \beta$ aggregation, and an in vitro study showed that the $A \beta$-copper complexation resulted in the formation of neurotoxic hydrogen peroxide. ${ }^{61}$ Furthermore, metals such as copper, iron, and zinc have been found in the amyloid deposits in the brains of AD patients. ${ }^{62}$ The use of metal chelators in the postmortem tissues of AD patients could dissolve these amyloid plaques. ${ }^{63} \mathrm{An}$ in vivo study with an animal model of AD also showed that chelating agents could solubilize amyloid plaques. ${ }^{64}$

According to the cholinergic hypothesis, the dysfunction of the cholinergic system is sufficient to produce a memory deficit in animal models that is similar to AD. ${ }^{65}$ Rossor et al and Henke and Lang reported that the brains of patients with AD showed the degeneration of cholinergic neurons and a reduction in cholinergic markers, whereas the activities of choline acetyltransferase (ChAT) and AChE were reduced in the cerebral cortexes of patients with AD ${ }^{66,67} \mathrm{~A}$ study reported by Soininen et al showed that $\mathrm{AD}$ patients carrying the apolipoprotein E (APOE) $\varepsilon 4$ allele have a more severe cholinergic deficit than the AD patients without the APOE $\varepsilon 4$ allele. ${ }^{68}$

Phospholipase A2 (PA2) is the enzyme responsible for the synthesis of chemical mediators of inflammation and is also responsible for the conversion of phosphatidylcholine to choline. ${ }^{69,70}$ However, PA2 has been reported to decrease in the frontal and parietal cortexes of AD patients, ${ }^{71}$ resulting in decreased levels of choline. Because choline is converted to acetylcholine by $\mathrm{ChAT}$ and $\mathrm{AChE}$, its deficit contributes to cholinergic deficiency and AD progression. ${ }^{70}$ 


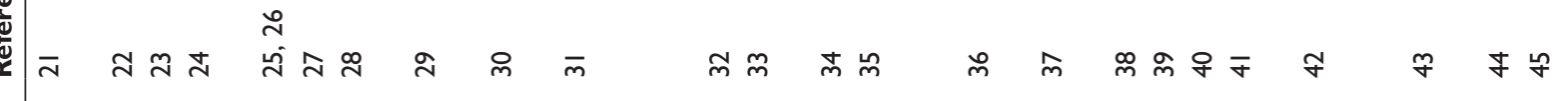

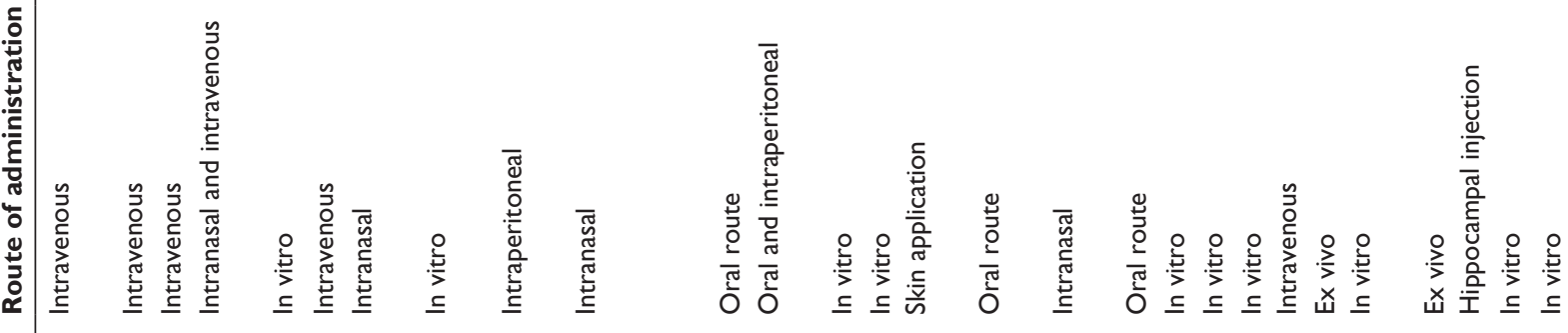




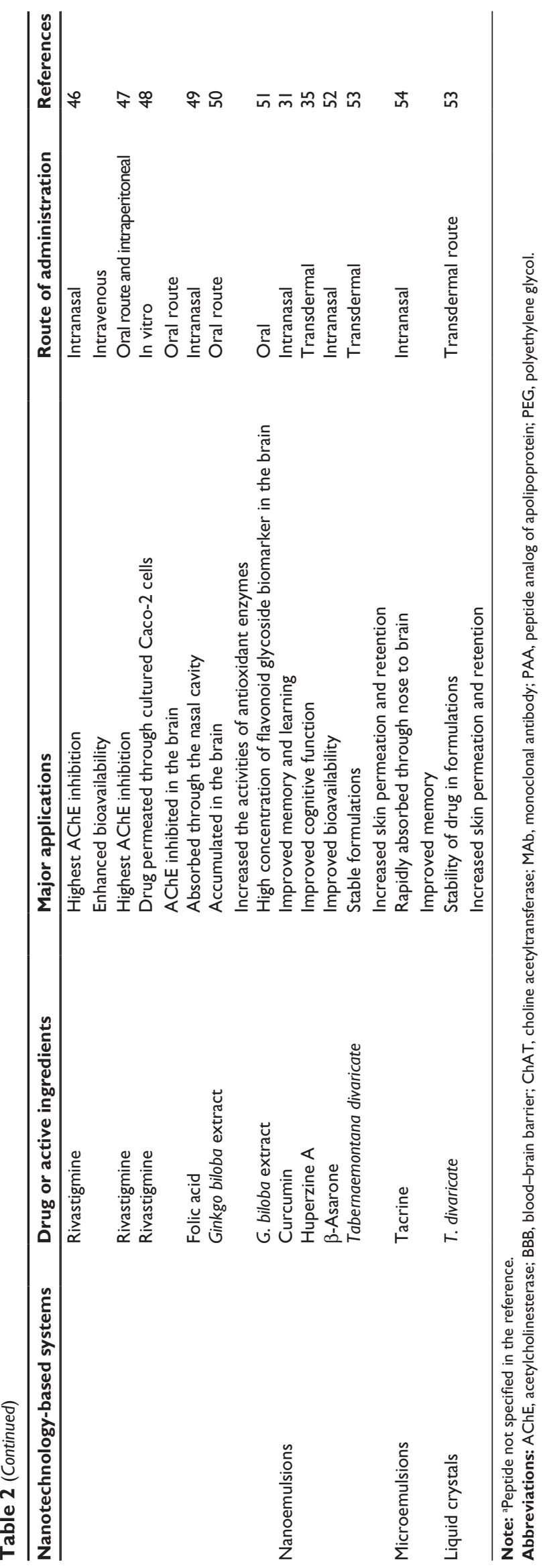

The main function of tau protein is to promote the association of tubulin monomers in order to form microtubules, which modulate the functional and structural organization of neurons. ${ }^{72}$ In $\mathrm{AD}$, tau protein is abnormally phosphorylated and thus the microtubules disaggregate, accumulating in the cell body and forming intracellular filaments that lead to the disorganization of the neuron cytoskeleton. ${ }^{73,74}$ This results in the blocking of the intracellular trafficking of neurotrophic proteins and other functional proteins, resulting in the loss or decline in dendritic or axonal transport in neurons (Figure 1B).

In $\mathrm{AD}$, the reactive astrocytes are increased, ${ }^{75,76}$ and there is a high expression of PA2. Astrocytes are able to release proinflammatory molecules, such as interleukins (ILs), prostaglandins, leukotrienes, thromboxanes, coagulation factors, complement factors, and proteases. ${ }^{77-80}$ The activated microglia cells have also been shown to be abundant in the brains of patients with $\mathrm{AD} .{ }^{76,79}$ These cells produce a variety of neurotoxic compounds, including superoxide radicals, glutamate, and nitric oxide ${ }^{81}$ The exposure of microglia cells to $\mathrm{A} \beta$ results in the release of proinflammatory factors, including interleukin-1 (IL-1), interleukin-6 (IL-6), interleukin-8 (IL-8), and tumor necrosis factor- $\alpha$ (TNF- $\alpha){ }^{82}$

A number of complex mechanisms are involved in the genesis and progression of AD. Recent advances in the understanding of the molecular control of these various pathways will allow for a more accurate diagnosis and assessment of $\mathrm{AD}$ prognosis and may lead to more novel approaches to finding new molecular targets for AD treatment and prevention.

\section{Diagnosis and treatment of AD}

$\mathrm{AD}$ is a clinical diagnosis; ${ }^{83-86}$ however, the differential diagnosis of $\mathrm{AD}$ is based on the diagnosis of depression, which occurs in approximately $30 \%-50 \%$ of patients with $\mathrm{AD}$. Depression in patients committed with $\mathrm{AD}$ are more often features motivational disturbances, such as fatigue, psychomotor slowing, and apathy, whereas depression in geriatric patients without cognitive impairment tends to feature mood symptoms, such as depressed mood, anxiety, suicidality, and disturbances in sleep and appetite. ${ }^{87}$ Commonly used instruments for assessing depression were designed for use in other patient populations and may be less reliable in patients with AD. ${ }^{87}$ Olin et al have proposed the inclusion and exclusion of provisional affective and behavioral diagnostic criteria in identifying $\mathrm{AD}$ in patients with depression. ${ }^{88}$

Ancillary imaging studies, such as computed tomography (CT) or magnetic resonance imaging (MRI) and, in selected 
A

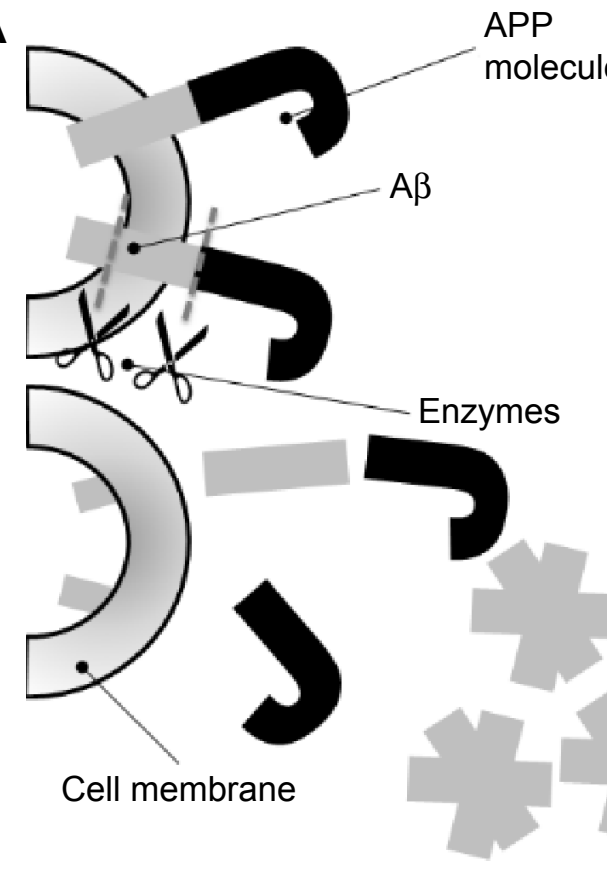

APP

\section{e}

.

(2)

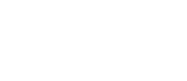

\section{Amyloid} plaques

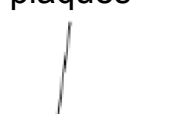

B Neurofibrillary tangles
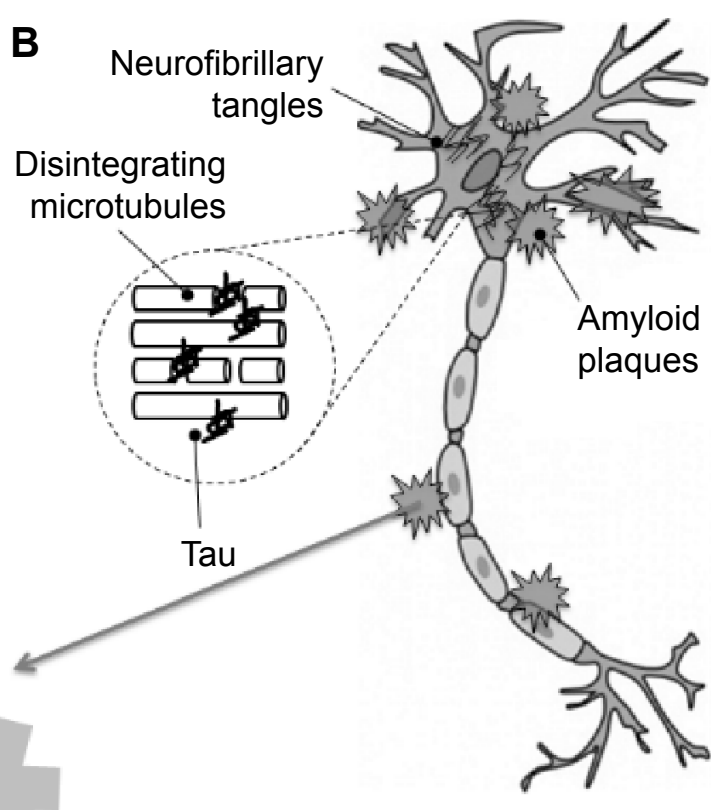

Figure I Formation of amyloid plaques (A) and neurofibrillary tangles (B) in the neurons in Alzheimer's disease. Abbreviations: $A \beta, \beta$-amyloid; APP, amyloid precursor protein.

cases, single-photon emission CT (SPECT) or positron emission tomography (PET), can also be used in the diagnosis of $\mathrm{AD} .{ }^{89}$ Brain MRI or CT scanning has indicated the use of structural neuroimaging to detect lesions that may result in cognitive impairment. In patients with $\mathrm{AD}$, brain MRIs or CT scans can show diffuse cortical and cerebral atrophy, but these findings are not diagnostic of AD. ${ }^{89}$

Images obtained from CT scans can show the changes in the rate of atrophy progression, ${ }^{90}$ longitudinal changes in brain size, ${ }^{91}$ and enlargement of the third and lateral ventricles. ${ }^{92}$ This approach can be useful in diagnosing AD. MRI measurements of the cerebral structures (hippocampus, amygdala, lateral ventricles, third ventricle, and basal forebrain) yield a prediction rate of $77 \%$ for the conversion of questionable $\mathrm{AD}$ to $\mathrm{AD} .{ }^{93,94}$ PET scanning is helpful for understanding the pathogenesis of $\mathrm{AD}$, making the correct diagnosis, and monitoring the $\mathrm{AD}$ progression and response to drug treatment. ${ }^{95}$ PET scanning involves the introduction of a radioactive tracer into the human body, usually via intravenous injection. PET measures glucose-dependent physiological processes in brain by using 2-[ $\left[{ }^{18} \mathrm{~F}\right]$ fluoro2-deoxy-D-glucose (FDG). ${ }^{96,97}$ Patients with AD have a temporoparietal glucose hypometabolism, which correlates with the severity of dementia and can be evaluated using FDG PET. ${ }^{96,98,99}$ In 2012, florbetapir F18 was approved by the US Food and Drug Administration (FDA) as a diagnostic imaging agent. It is indicated for PET brain imaging of $A \beta$ neuritic plaques in adults under evaluation for $\mathrm{AD}$ or other conditions related to cognitive decline. ${ }^{100-103}$ In 2013, the FDA approved flutemetamol F18. Like florbetapir F18, this drug attaches to $A \beta$ in the brain and produces a PET image that can be used to assess the presence of $A \beta$, as evidenced in a clinical Phase II trial. ${ }^{104}$

Laboratory tests can be used to exclude other possible causes for dementia ${ }^{89}$ such as cerebrovascular disease, cobalamin deficiency, syphilis, or thyroid disease. ${ }^{105-107}$ Cerebrospinal fluid (CSF) analysis can be useful in identifying dementia caused by other factors, including infections in the central nervous system (CNS) such as neurosyphilis, neuroborreliosis, and cryptococcosis. ${ }^{108}$ The CSF levels of tau and phosphorylated tau are often elevated in $\mathrm{AD}$, whereas amyloid levels are usually low. The reason for this is not known, but perhaps amyloid levels are low because the amyloid is deposited in the brain rather than the CSF. ${ }^{86}$ Other diagnosis tools include genotyping mutations in the genes for APOE, APP, and PS. A recent study has reported that plasma levels of APOE $\varepsilon 4$ are associated with the risk of dementia independent of the APOE genotype. ${ }^{109}$ These genotype tests provide assessments to patients with $\mathrm{AD}$ and provide the key elements used in genetic counseling for the disease. ${ }^{110}$

The use of nanotechnology as a diagnostic tool depends on the detection of amyloid peptides $(A \beta)$, which are used as targets in the development of biological markers for the diagnosis of $\mathrm{AD}$. 
Polymeric nanoparticles (NPs) have been prepared and encapsulated with radio-labeled ${ }^{125}$ I-clioquinol (5-chloro-7iodo-8-hydroxyquinoline [CQ]), a drug with amyloid affinity, to improve its transport to the brain and amyloid plaque retention of ${ }^{125} \mathrm{I}-\mathrm{CQ}$. Radio-iodinated CQ NPs have been demonstrated to be promising delivery vehicles for in vivo SPECT or for use as a PET amyloid imaging agent. ${ }^{11}$

The use of thioflavin-T entrapped in polymeric NPs has been described for use as a probe to detect $A \beta$ in senile plaques. ${ }^{12}$ The photoconversion of fluorescent thioflavin- $\mathrm{T}$ as a model drug was achieved in tissues fixed 3 days after injection, and thioflavin-T delivered from nanospheres was predominantly found in neurons and microglia. These data suggest that drugs delivered by NPs might target $A \beta$ in the brain. ${ }^{12}$

The current pharmacological approach to $\mathrm{AD}$ treatment is based on vascular prevention and symptomatic therapy with cholinesterase inhibitors and $\mathrm{N}$-methyl-D-aspartate (NMDA) antagonists. ${ }^{113}$ Cholinesterase inhibitors are included in drugs such as donepezil, rivastigmine, galantamine, ${ }^{113}$ and tacrine. ${ }^{114}$ These drugs act by inhibiting the action of AChE and optimizing the levels of acetylcholine available for postsynaptic stimulation. ${ }^{115}$

Memantine is an NMDA antagonist that acts as a noncompetitive glutamate receptor antagonist. ${ }^{116,117}$ Glutamaterelated excitotoxicity resulting from an excessive activation of neuronal amino acid receptors ${ }^{118}$ is involved in the pathophysiology of AD. ${ }^{119}$ Memantine acts on the glutamatergic system by blocking NMDA receptors and this blocking effects on glutamate activity reduction on brain cells and blocking the activity of the neurotransmitter. ${ }^{120,121}$ At normal levels, glutamate is conducive to memory and learning, but if levels are too high, glutamate appears to overstimulate nerve cells, killing them through excitotoxicity. ${ }^{122}$ The interaction of memantine with NMDA receptors plays a major role in the symptomatic improvement that the drug produces in AD. Moreover, there is no evidence as yet that the ability of memantine to protect against NMDA receptor-mediated excitotoxicity has a disease-modifying effect in $\mathrm{AD}$, although this has been suggested in animal models. ${ }^{123}$

Winslow et al have reported conflicting evidence about the benefits of selegiline, testosterone, and ginkgo (Ginkgo biloba) for the treatment of $\mathrm{AD}$, and no evidence supports the beneficial effects of vitamin E, estrogen, or nonsteroidal anti-inflammatory drug therapies. ${ }^{114}$ Nevertheless, the inflammatory pathways in $\mathrm{AD}^{124,125}$ and treatment with antiinflammatory molecules has the potential to delay, prevent, or treat $\mathrm{AD} .{ }^{125,126}$

\section{Nanotechnology-based drug delivery systems}

Treatment options are limited mainly due to the inability of drugs to cross the blood-brain barrier (BBB) ${ }^{127-129}$ or their poor solubilities by oral route. ${ }^{130,131}$ Many strategies have been developed to overcome the BBB, such as drug delivery systems, liposomes, polymeric and solid lipid NPs (SLNs), solid lipid carriers, liquid crystals (LCs), microemulsions (MEs), and hydrogels. ${ }^{127-129,132-134}$ The physicochemical characteristics of drugs, such as its hydrophilicity or lipophilicity, ionization, high molecular weight, poor bioavailability, extensive metabolization, and adverse effects, can result in its failure as a pharmacotherapeutic. ${ }^{127,135}$ These limitations can be overcome by the use of intranasal administration, which offers an alternative, noninvasive means of drug delivery to the brain because drugs delivered this way can bypass the BBB and directly transport drugs to the CNS. ${ }^{136,137}$

\section{Polymeric NPs}

NPs are defined as particulate dispersions or solid particles with sizes ranging from 1 to $1,000 \mathrm{~nm} .{ }^{138}$ The structural organization of a nanosystem is based on its composition: the presence of compartments within nanocapsules ${ }^{139}$ leads to oily or aqueous cores surrounded by thin polymer membranes, ${ }^{140}$ whereas nanospheres provide a matrix-based organization of the polymeric chains (Figure 2). ${ }^{139}$

NPs have been prepared using several methods, including polymer polymerization, ${ }^{141,142}$ ionic gelation or coacervation, ${ }^{143,144}$ emulsion solvent evaporation, ${ }^{145-148}$ spontaneous emulsification or solvent diffusion, ${ }^{149,150}$ nanoprecipitation, ${ }^{151,152}$ spray drying, ${ }^{29,153}$ supercritical fluid technology, ${ }^{154}$ and particle replication in non-wetting templates (PRINT). ${ }^{155-157}$

Drug delivery across the BBB to the brain may provide a significant advantage over currently used strategies without damaging the BBB. ${ }^{158,159}$ The transport mechanism of NPs across the BBB can be explained by the increased retention of the NPs in the brain blood capillaries in combination with the adsorption of the NPs to the capillary walls. These events lead to a higher concentration gradient, which increases the transport across the endothelial cell layer and thus enhances the delivery to the brain. ${ }^{160}$ Transport can also be facilitated through the inhibition of the efflux system ${ }^{160}$ by using polysorbate 80 as the coating agent. ${ }^{161,162}$ NPs may induce local toxic effects on the brain vasculature, leading to a limited permeabilization of the brain endothelial cells. ${ }^{160}$ The use of a surfactant to solubilize the lipids of the endothelial cell membrane can enhance drug permeability across the 


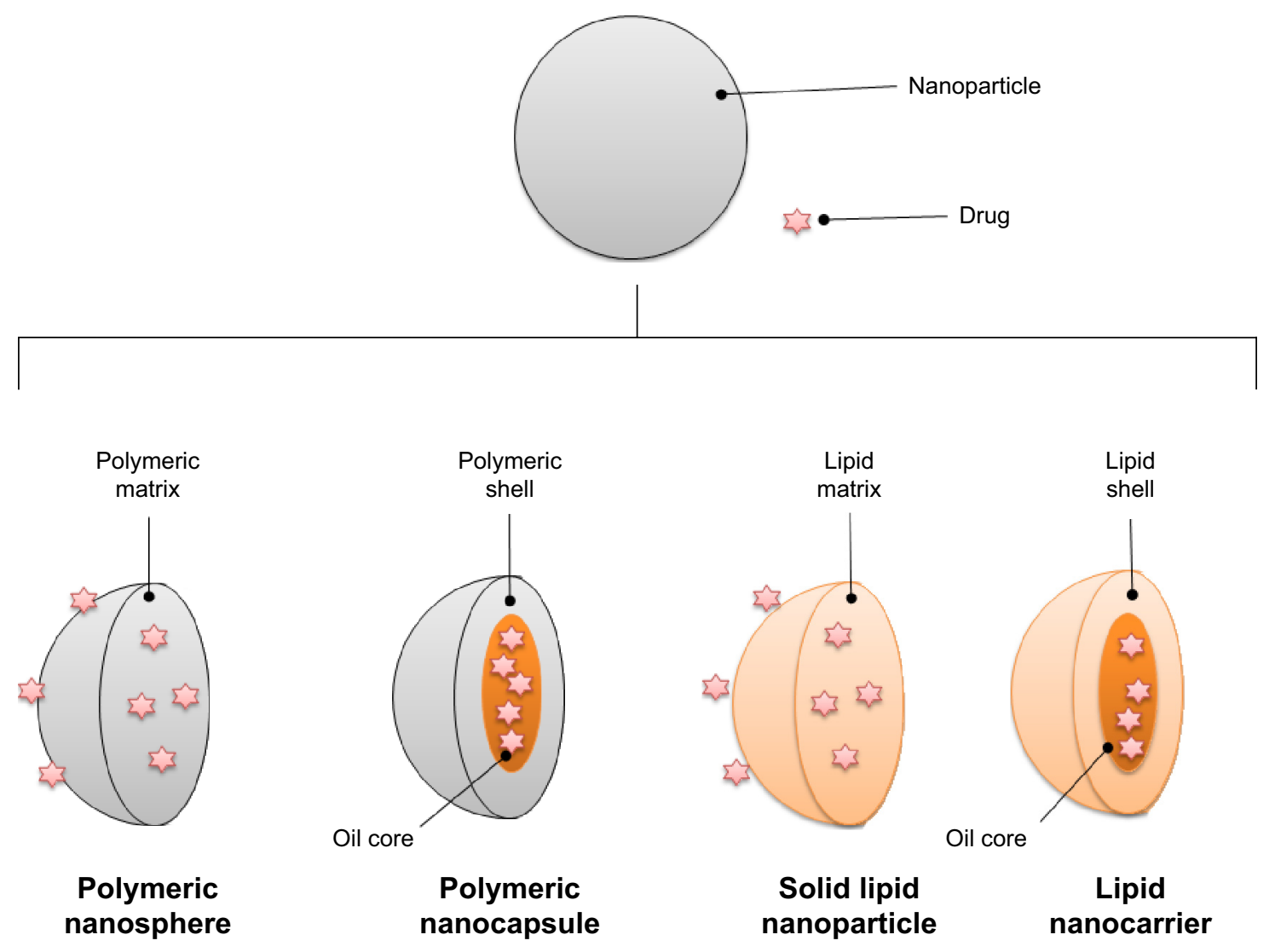

Figure 2 Schematic differences between nanocapsule, nanostructured lipid carrier, polymeric nanoparticle, and solid lipid nanoparticle drug delivery systems.

BBB. The NPs could permeate the BBB through the tight junctions, which are open between the endothelial cells of the brain blood vessels. ${ }^{158,160,163}$ Endocytosis by the endothelial cells followed by the release of the drugs within these cells facilitates delivery to the brain. ${ }^{164,165}$ Transcytosis can also facilitate transport through the endothelial cell layer. ${ }^{166-168}$ Finally, a combination of the effects described above can be used (Figure 3). ${ }^{158,160,163}$ NPs can also be administered nasally to promote absorption ${ }^{169}$ and delivery to the brain. ${ }^{160,170,171}$ Other technological strategies include coating NPs with polyethylene glycol (PEG), ${ }^{172}$ polymers, or antibodies to improve nasal absorption. ${ }^{173}$ Surface modification of the NPs with mucoadhesive polymers can increase the retention time of NPs delivered via the nasal route. ${ }^{174}$

Wilson et $\mathrm{al}^{21}$ developed polysorbate 80 -coated $\operatorname{poly}(n$ butyl cyanoacrylate) NPs loaded with tacrine, which were prepared by emulsion polymerization. The concentrations of tacrine in the lungs and kidneys were not significant when compared to both groups. The authors suggested a mechanism for delivery of the coated polysorbate $80 \mathrm{NPs}$ to the brain via the interaction between the polysorbate 80 coating and the endothelial cells of the brain microvessels. ${ }^{21}$ In another study, Wilson et $\mathrm{al}^{22}$ developed poly( $n$-butyl cyanoacrylate) NPs coated with polysorbate 80 for the targeted delivery of rivastigmine to the brain in order to treat AD. Animal studies were performed by injecting the NPs into mice. The concentration of tacrine in the brain was approximately $170 \mathrm{ng} / \mathrm{mL}$ when the coated NPs were used, and this result was significant $(P<0.001)$ relative to the use of uncoated NPs or the free drug. The authors suggest that the mechanism for delivering the coated polysorbate $80 \mathrm{NPs}$ to the brain is the interaction between the polysorbate 80 coating and the endothelial cells of the brain microvessels. ${ }^{22}$ This specific role of the polysorbate 80 coating in targeting NPs to the brain was proposed and studied by Sun et al. ${ }^{175}$

Zhang et a $^{23}$ developed a dual-functional NP drug delivery system based on a PEGylated poly(lactic acid) polymer containing two targeting peptides, TGN and QSH, conjugated to the surfaces of the NPs. TGN specifically targets ligands at the $\mathrm{BBB}$, while QSH has good affinity for $\mathrm{A} \beta_{1-42}$, which is the main component of amyloid plaques. In this study, the optimal maleimide/peptide molar ratio was 3 for both TGN and QSH on the surface of the NPs. These NPs were delivered to amyloid plaques with enhanced and precisely targeted delivery in the brains of AD model mice. ${ }^{23}$ 


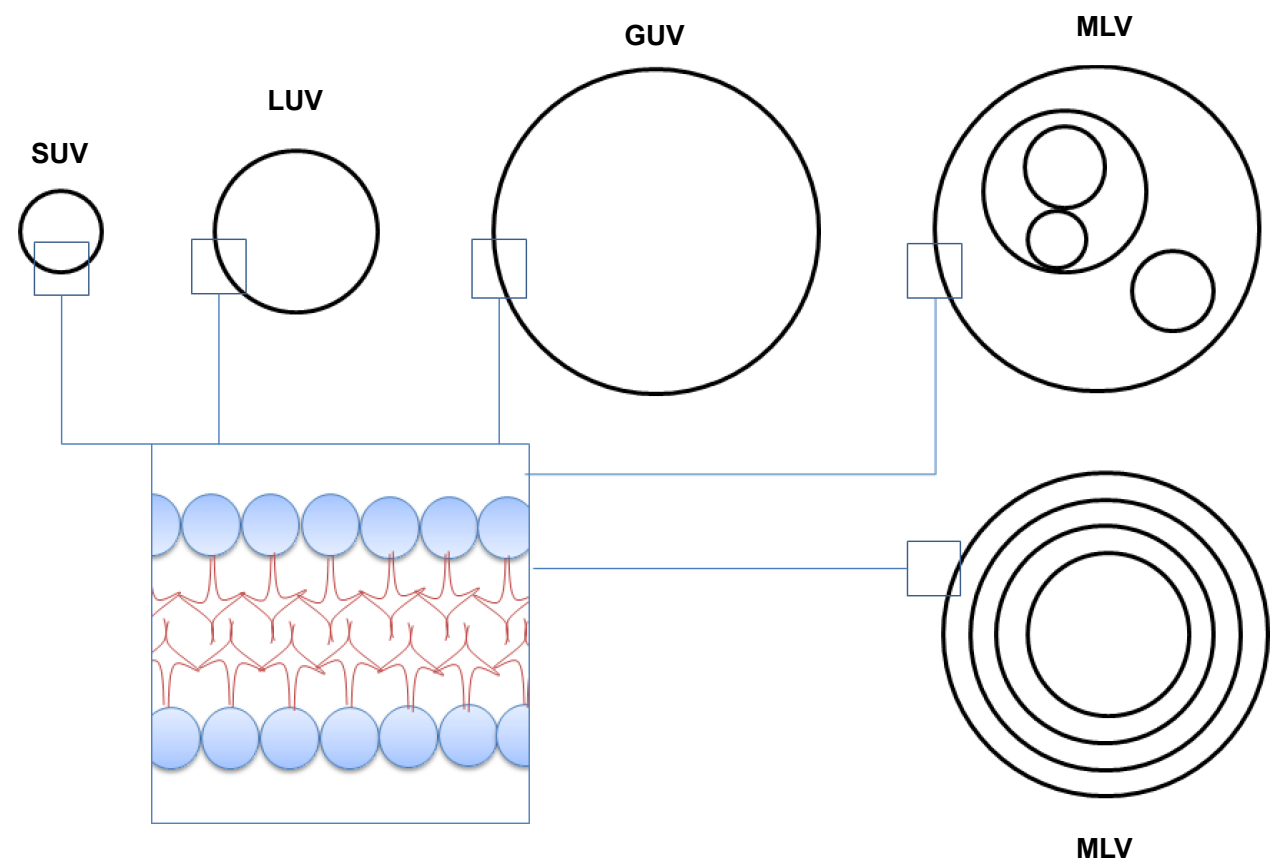

Figure 3 Schematic representation of types of liposomes and enlarged view of the layers of phospholipids.

Abbreviations: GUV, giant unilamellar vesicle; LUV, large unilamellar vesicle; MLV, multilamellar vesicle; SUV, small unilamellar vesicle.

The use of intranasal NPs to deliver basic fibroblast growth factor (bFGF) to the brain for the treatment of $\mathrm{AD}$ was also studied by Zhang et al. ${ }^{24}$ In this study, bFGF was entrapped in NPs conjugated with PEG and polylactide-polyglycolide (PLGA) and Solanum tuberosum lectin (STL), which selectively binds to $N$-acetylglucosamine on the nasal epithelial membrane to facilitate brain delivery. The NPs were prepared using the emulsion solvent evaporation method. The intranasal administration of the STL-modified NPs (STL-bFGF-NPs) resulted in a 1.7-5.17-fold greater distribution of the formulation in the brain than the intravenous administration of the NPs. The distribution of the formulation using intranasally administered STL-bFGF-NPs was also 0.61-2.21-fold greater than an intranasally administered drug solution and $0.19-1.07$-fold greater than intranasally administered unmodified NPs. The activity of ChAT in mice showed a significant increase $(P<0.05)$ in the group treated with NPs via the intranasal route compared to the $\mathrm{AD}$ control group. These findings indicated that ChAT activity in the hippocampus of $\mathrm{AD}$ rats treated with bFGF-loaded STL-conjugated NPs was higher than in the rats treated with unconjugated NPs. The STL-conjugated NPs could effectively facilitate the direct transport of bFGF into the rat brain with reduced peripheral adverse effects following intranasal administration. ${ }^{24}$ Based on these requirements, PEG-PLGA copolymer NPs that feature a PEG-rich surface around the PLGA core are ideal for intranasal administration because the PEG-rich surface has been demonstrated to prevent the NP aggregation typically observed when the uncoated PLGA NPs come into contact with the nasal mucosa. ${ }^{176}$

Poly[(hexadecyl cyanoacrylate)-co-methoxypoly (ethylene glycol) cyanoacrylate] NPs were formulated by Brambilla et al. ${ }^{25,26}$ The authors investigated the effects of these NPs in slowing down or disrupting the aggregation process in vitro through kinetic studies performed with the $A \beta_{1-42}$ peptide or corresponding oligomers by capillary electrophoresis. The capillary electrophoresis experiments showed that these NPs could link the $A \beta_{1-42}$ peptide both under its monomeric and soluble oligomeric forms. These NPs were also shown to influence $A \beta_{1-42}$ peptide aggregation, which was confirmed by thioflavin-T assays.

Joshi et $\mathrm{al}^{27}$ used a modified nanoprecipitation method and an emulsion polymerization method to prepare rivastigmineloaded PLGA and PBCA NPs, respectively. The administration of rivastigmine formulations in saline-treated animals did not result in any noticeable improvement in learning and memory capacities, whereas the administration of different rivastigmine-loaded NPs in scopolamine-treated mice antagonized the scopolamine-induced amnesia, as evidenced by a significant decrease $(P<0.05)$ in escape latency.

Fazil et $a 1^{28}$ prepared chitosan NPs using an ionic gelation method to enhance the bioavailability and uptake of rivastigmine to the brain via intranasal delivery. Using confocal laser scanning fluorescence microscopy, their findings showed 
that the concentration of rivastigmine in the brain following intranasal administration was found to be significantly higher at all times compared to the administration of a rivastigmine solution via the intravenous or intranasal route. ${ }^{28}$

Amorim et al used the spray-drying technique to develop idebenone-loaded chitosan and $N$-carboxymethylchitosan NPs. ${ }^{29}$ Although the authors did not study the use of these NPs in the treatment of $\mathrm{AD}$, the beneficial effects of idebenone for the treatment of $\mathrm{AD}^{177,178}$ and its role as an antioxidant in $\mathrm{AD}$ progression ${ }^{55,58,179-181}$ have been well documented in clinical trials. The incorporation of idebenone in chitosan or $\mathrm{N}$-carboxymethylchitosan NPs was shown to preserve the antioxidant efficiency, especially at higher polymer-to-drug ratios. The NPs showed a tenfold increase in drug stability compared to the free drug. These results showed a severe reactivity of free idebenone that was similar to the positive control, indicating a significant potential for corrosion or irritation. On the other hand, the incorporation of idebenone in polymeric NPs showed a decrease in drug reactivity. ${ }^{29}$ Because chitosan and $N$-carboxymethylchitosan exhibit mucoadhesive properties, ${ }^{182-187}$ these results revealed that NPs are potential carriers for the nasal delivery of hydrophobic and irritating drugs such as idebenone due to the high firstpass metabolism of idebenone ${ }^{188}$ after oral administration.

\section{Solid lipid carriers}

SLNs are typically spherical, with average diameters between 10 and 1,000 $\mathrm{nm}$ when dispersed in water. SLNs possess a solid lipid core matrix that can solubilize lipophilic molecules. ${ }^{189}$ The lipid core, typically consisting of triglycerides (eg, tristearin), diglycerides (eg, glyceryl behenate), monoglycerides (eg, glycerol monostearate), fatty acids (eg, stearic acid), steroids (eg, cholesterol), or waxes (eg, cetyl palmitate), ${ }^{190}$ is stabilized by surfactants, though the combination of emulsifiers might be more efficient at preventing particle agglomeration. ${ }^{190}$ Though SLNs are formed by a matrix lipid, a new generation of NPs can be produced using a blend of solid lipids with a liquid lipid, termed nanostructured lipid carriers (NLCs), ${ }^{189,191}$ in order to minimize the drug expulsion associated to SLNs (Figure 2).

SLNs or NLCs are prepared from lipids, an emulsifier, and water or solvent by using different methods such as high pressure homogenization, ${ }^{192,193}$ an ultrasonication/high-shear technique, ${ }^{194-198}$ the solvent evaporation method, ${ }^{199,200}$ the solvent emulsification-diffusion method, ${ }^{201-204}$ the supercritical fluid method, ${ }^{205,206}$ the ME-based method, ${ }^{207-209}$ the spray-drying method, ${ }^{210-212}$ the double emulsion method, ${ }^{213}$ or the precipitation technique. ${ }^{214}$
The BBB can be overcome through the use of SLNs or nanocarriers lipids for the delivery of drugs to the brain, as these formulations can penetrate the $\mathrm{BBB}^{194}$ or be used intranasally to bypass the BBB. The use of cationic lipids can be a strategy to improve mucoadhesion in the nasal cavity by promoting electrostatic interactions with mucus ${ }^{215}$ in addition to mediating the adsorptive-mediated transcytosis cationic NPs across the BBB. ${ }^{216}$ Coating NPs with surfactants can be an alternative strategy for delivery across the BBB. The transport of surfactant-coated NPs across the BBB may occur through endocytosis mediated by the endothelial cells of the brain capillaries. ${ }^{217-219}$

Piperine SLNs with a polysorbate 80 coating were prepared by the emulsification-solvent diffusion technique. ${ }^{30}$ These NPs were experimentally assessed in ibotenic acidinduced AD in mice. The results showed an increase in $\mathrm{AChE}$ activity and improvement in cognition, which were superior to the result shown for donepezil. Histopathology studies also revealed a reduction in plaques and tangles. ${ }^{30}$

Sood et $\mathrm{al}^{31}$ developed curcumin/donepezil-loaded NCLs for delivery to the brain via the intranasal route. The results demonstrated a higher concentration of drugs in the brain via intranasal delivery compared to intravenous administration. A mouse model showed improved memory and learning compared to the group treated with the free drug. Nevertheless, the levels of acetylcholine were improved and oxidation damage was reduced in the groups treated with NLCs. ${ }^{31}$

Zhuang et $\mathrm{al}^{32}$ formulated vinpocetine-loaded NCLs using a high-pressure homogenization method for improved oral bioavailability. Pharmacokinetic studies showed a twofold increase, threefold increase, and 0.35 -fold decrease in the maximum concentration, maximum time, and elimination constant in plasma, respectively, relative to a suspension of vinpocetine. The authors concluded that the NCLs showed a relative drug bioavailability of $322 \%$ in rats after oral administration compared with the administration of free drug in suspension, further demonstrating that these NCLs can be used to load drugs with poor water solubility. ADbased clinical trial has shown that vinpocetine is a drug with potential use in the treatment of cognitive impairment and memory. ${ }^{220}$ However, a 2003 Cochrane Review determined that the results were inconclusive. ${ }^{221}$

NCLs with oil-based cores loaded with resveratrol were developed by Frozza et al in order to improve cerebral bioavailability. ${ }^{33}$ The results showed 2.5-fold, 6.6-fold, and 3.4-fold greater drug concentrations in the brain, liver, and kidneys, respectively, of mice treated with the NCLs relative to those treated with free resveratrol. ${ }^{33}$ Additional 
important data showed that mice treated with an intracerebral infusion of $A \beta_{1-42}$ had memory deficits that were reduced only by the treatment with drug-loaded NCLs with oil-based cores. ${ }^{33}$ Recently, a study using resveratrol confirmed the accumulation of this drug in vivo and the neuroprotective action of a kinase against $A \beta$ plaques. ${ }^{222}$ This study demonstrates the emerging therapeutic potential of resveratrol in AD.

Bondi et $\mathrm{al}^{223}$ developed ferulic acid-loaded SLNs using the $\mathrm{ME}$ technique as a potential treatment for $\mathrm{AD}$. In this study, unloaded SLNs showed no cytotoxicity against human neuroblastoma, but they showed the ability to penetrate into these cells. Cells treated with ferulic acid-loaded SLNs showed a greater reduction in the production of radical oxygen species than cells treated with the free drug. ${ }^{223}$ These findings demonstrate that drug-loaded SLNs possess a higher protective activity than the free drug against oxidative stress induced in neurons, suggesting that these SLNs are potentially excellent carriers for transporting cholinergic agent drugs into the cells.

Patel et al proposed a study to comparatively evaluate the in vitro and in vivo behaviors of huperzine A-loaded lipid-based nanocarriers. ${ }^{35}$ Huperzine $\mathrm{A}$ is a well-tolerated drug that has been shown in a clinical study to effectively reverse or attenuate cognitive deficits. ${ }^{224}$ Huperzine A was loaded on SLNs and NLCs, which were prepared using the ME technique before the nanocarriers were dispersed on a gel. Ex vivo permeation studies were carried out, and the results showed that NLCs had increased permeability through the abdominal rat skin relative to SLNs. A primary irritation test in rabbit model indicated the safety of applying the drug-loaded nanocarrier-based gel to skin. The in vivo efficacies of the nanocarrier-based formulations were also tested in a scopolamine-induced amnesia model. A significant improvement in cognitive function was observed in mice treated with the nanocarrier-based formulations compared with the control group. A decrease in cognitive function was observed upon oral delivery of a drug suspension compared with the transdermally administered nanocarrier. These findings showed a reduced transfer latency over the period of 3 days, which indicated the sustained and controlled release of the drug from the developed nanocarriers when administered via the transdermal route. ${ }^{223}$

Studies have demonstrated that curcumin decreases the in vitro and in vivo $A \beta$ formation from APP and also inhibits the aggregation of $A \beta$ into pleated sheets. ${ }^{225-228}$ Curcumin has been incorporated into SLNs and NCLs for other therapeutic purposes. ${ }^{229-234}$ Kakkar et al evaluated curcumin-loaded SLNs for brain delivery in rats via the oral route. ${ }^{36}$ The results showed that drug-loaded SLNs increased the activity of AChE compared to the free drug, and the concentration of curcumin was increased by twofold in the brain compared to the free drug when both treatments were orally administered. Although a cerebral ischemic reperfusion injury animal model was used in the study, these SLNs can be used for drug release in the brain for the treatment of AD. ${ }^{36}$ SLNs and NCLs that are chosen as drug carriers and administered in vivo can be transported to the $\mathrm{CNS}^{34,165,194,235-238}$ and may be useful in the treatment of AD.

\section{Liposomes}

Liposomes are vesicles consisting of one or more phospholipid bilayers concentrically oriented around an aqueous compartment $^{239}$ that serve as carriers of lipophilic or hydrophilic drugs. ${ }^{240,241}$ Various processes can be used to prepare liposomes, such as hydration of a thin lipid film ${ }^{242-244}$ followed by agitation, ${ }^{245-248}$ sonication, ${ }^{249-254}$ extrusion, ${ }^{251,255-258}$ high-pressure homogenization, ${ }^{259-262}$ or reverse-phase evaporation. ${ }^{263-266}$

Liposomes may contain a single lipid bilayer or multiple bilayers around the inner aqueous compartment and are therefore classified as unilamellar and multilamellar, respectively. ${ }^{267}$ Liposomes are classified by their lamellar size as small unilamellar vesicles with diameters of 20-100 nm, large unilamellar vesicles with diameters exceeding $100 \mathrm{~nm}$, giant unilamellar vesicles with diameters up to $1 \mu \mathrm{m}$, oligolamellar vesicles with diameters of $0.1-1 \mu \mathrm{m}$, and multilamellar vesicles with diameters up to $500 \mathrm{~nm}$ (Figure 4). ${ }^{268}$

In the literature, liposomes are classified as niosomes, transfersomes, ethosomes, and phytosomes. Niosomes are formed by self-assembly of nonionic surfactants in an aqueous dispersion and they are flexible and more stable than liposomes, which reduces the flux of drugs in comparison to conventional liposomes. ${ }^{269}$ Transfersomes are deformable vesicles composed of phospholipids ${ }^{270}$ that are usually administered via the transdermal route. ${ }^{271}$ Ethosomes are either conventional liposomes or are transfersomes containing up to $10 \%$ ethanol, which can promote the solubilization of hydrophilic drugs. ${ }^{272}$ Phytosomes are produced by binding individual components of herbal extracts to phosphatidylcholine. $^{273}$

Yang et al formulated rivastigmine liposomes and cellpenetrating peptide (CPP)-modified liposomes to improve the distribution of rivastigmine in the brain, enhance the pharmacodynamics via intranasal administration, and minimize side effects. ${ }^{37}$ The results showed that the concentrations of rivastigmine across the $\mathrm{BBB}$ were significantly 


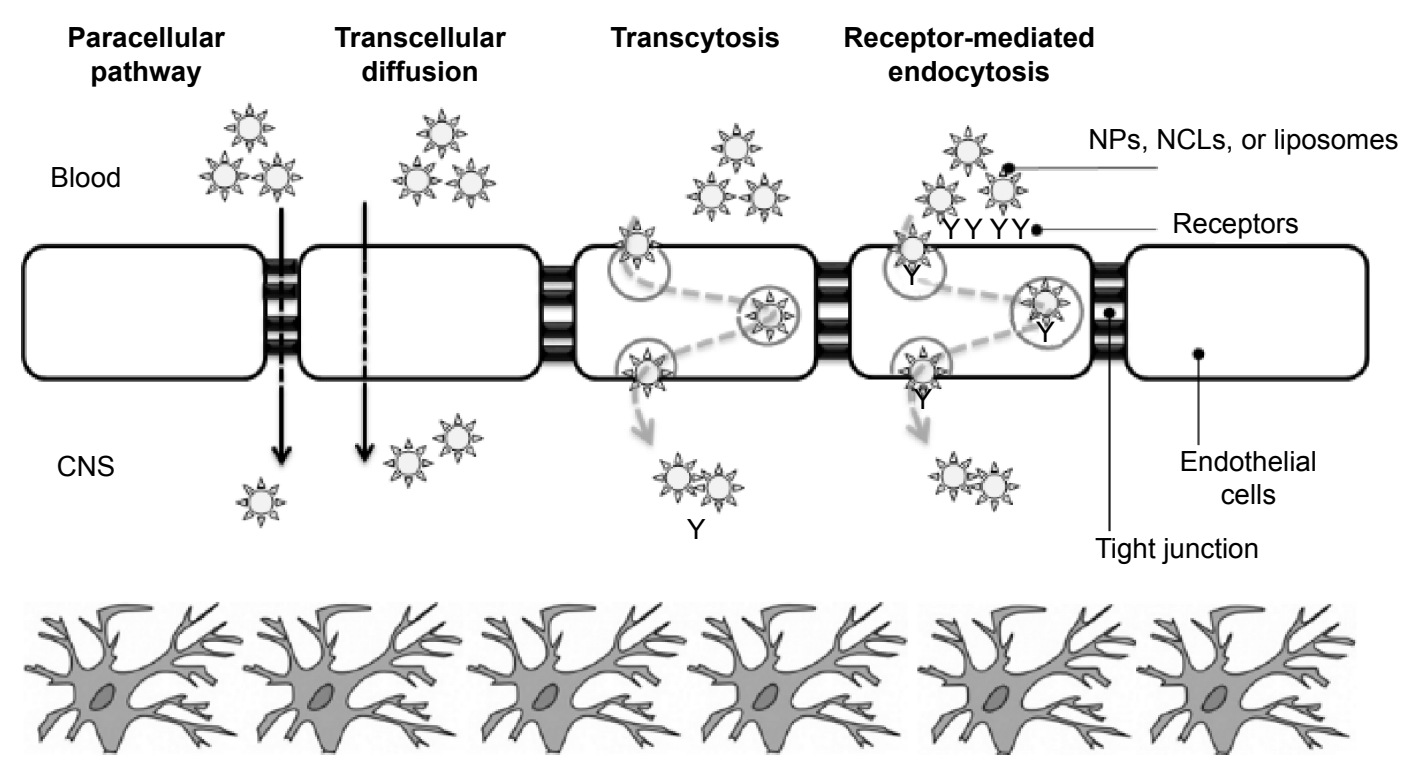

Figure 4 Main pathways for nanosystems to cross the blood-brain barrier to target to brain. Abbreviations: CNS, central nervous system; NCLs, nanostructured lipid carriers; NPs, nanoparticles.

different after 8 hours, reaching higher concentration values when CPP liposomes and liposomes were used compared to the free drug. The biodistribution of rivastigmine in the cerebellum was not found when free drug was administered intranasally or intravenously. The average rivastigmine concentration in CNS cerebral tissues was higher following intranasal administration of modified liposomes compared with liposomes, and the average rivastigmine concentration was significantly higher for the modified liposomes in the hippocampus, cortex, and olfactory region at 15 minutes to 60 minutes. The authors suggest that rivastigmine-loaded liposomes, especially-modified liposomes, improve the brain delivery and enhance pharmacodynamics with respect to BBB penetration and the nasal olfactory pathway into the brain after intranasal administration. ${ }^{37}$

In a study designed by Kumaraswamy et al, liposomes were obtained using the thin-film hydration technique. ${ }^{39}$ Thermal studies showed that the beta-sheet blocker was located in the hydrophobic core, where it acted to lower the surface tension. This property made these liposomes a suitable therapeutic agent for the prevention of amyloid aggregation by binding with $A \beta$ in the brain. ${ }^{39}$

Many techniques are used to target liposomes across the BBB. These strategic techniques include the conjugation of drugs and monoclonal antibodies against endogenous receptors in the BBB B $^{173,274,275}$ or liposomes or other nanodevices coated with polysorbate 80 , cationic macromolecules, peptides, or antibodies against $\mathrm{BBB}$ receptors or $\mathrm{A} \beta$ peptides ${ }^{173,276-279}$ to cross the $\mathrm{BBB}$ and to be targeted to the brain.
Liposomes functionalized with an anti-transferrin receptor antibody can cross the BBB. The functionalization of liposomes gave higher values of uptake and permeability across the barrier model in comparison to non-decorated liposomes. ${ }^{280}$ Liposomes were functionalized with a modified cell-penetrating TAT peptide, which increased the permeability of curcumin-loaded liposomes across a BBB model. ${ }^{40}$

Mono- and dual-decorated liposomes were prepared by immobilization of anti-transferrin monoclonal antibody $(\mathrm{MAb})$ against transferrin receptor in $\mathrm{BBB}$ and a peptide ana$\log$ of apolipoprotein (PAA) to target low-density lipoprotein receptor in BBB. The major results showed liposome uptake and transport across the human microvascular endothelial cells (hCMEC/D3) used as a model barrier was significantly affected by decoration with PAA or MAb, and that the double immobilization with ligands in the liposomes exerted an additive effect in the BBB targeting. The mechanism of targeting was confirmed to be vesicle transcytosis. In vivo study was carried out in mice, and the results showed that MAb and dual ligands (MAb and PAA) increased brain targeting compared to nontargeted liposomes. The authors appointed a contradiction between in vitro and in vivo results. PAA was found to target $\mathrm{BBB}$ and increase the in vitro targeting potential of MAb-decorated liposomes, but not in vivo, because in vitro studies were carried out in the presence of serum proteins in the middle of cell culture, revealing their important role in targeted-nanoformulation performance. ${ }^{41}$

Another published study explored the use of MAb in liposomes loaded with curcumin analog. This study compared 
the ability of both curcumin analog- and curcumin-loaded liposomes and showed a high affinity for senile plaques on postmortem brain tissue of AD patients. The ability of both liposomes to delay $\mathrm{A} \beta_{1-42}$ peptide aggregation was confirmed. However, the decoration of the curcumin-derivative liposomes with the MAb improved significantly the intake by the BBB cellular model. These results prove the potential of such multifunctional liposomes for application in $\mathrm{AD}$ treatment and diagnosis. ${ }^{42}$

Curcumin-conjugated liposomes were developed and the results showed significant amounts of labeled $A \beta$ deposits in postmortem brain tissue of $\mathrm{AD}$ patients. In vivo injection in the hippocampus and in the neocortex of mice showed that curcumin-conjugated nanoliposomes were able to specifically stain the $A \beta$ deposits. ${ }^{43}$ Thus, these liposome formulations can be applied in diagnosis and targeted drug delivery in AD.

Curcumin derivative maintaining the planarity was developed to obtain conjugated liposomes. Surface plasmon resonance experiments indicated that the liposomes exposing the curcumin derivative had extremely high affinity for $\mathrm{A} \beta_{1-42}$ fibrils, likely because of the occurrence of multivalent interactions, whereas those exposing non-planar curcumin did not bind to $\mathrm{A} \beta_{1-42}{ }^{44}$

Ligand-functionalized nanoliposomes for targeted delivery of galantamine have also been designed. The major result revealed by confocal microscopy was that the ligand-functionalized nanoliposomes facilitated galantamine uptake into PC12 neuronal cells. ${ }^{45}$ Nevertheless, in vivo uptake studies should be should be performed as well as testing in animal models of AD to demonstrate the effectiveness of the nanosystem.

Liposomes were prepared by the lipid hydration method to sustain the effect of rivastigmine in the brain. Rivastigmine-loaded liposomes and rivastigmine solution were administered via the subcutaneous route in an aluminum chloride-induced Alzheimer's model. Both formulations improved the deterioration of spatial memory induced by aluminum chloride, with liposomes having a superior effect. Though the rivastigmine solution significantly attenuated AChE activity, rivastigmine-loaded liposomes succeeded in normalizing AChE. ${ }^{38}$

The delivery of liposomes to the brain can be attained via the intranasal route to overcome the $\mathrm{BBB},{ }^{169,281,282}$ and liposomes can cross the BBB by transport lipid-mediated free diffusion or lipid-mediated endocytosis. ${ }^{283}$ Rivastigmineloaded liposomes were prepared using the lipid hydration method for delivery into the brain via the intranasal route. Intranasally delivered liposomes were compared to the orally delivered free drug group. The results showed that maximum concentration was tenfold higher in plasma and the half-time was significantly different for the intranasally delivered liposome group compared to the intranasally delivered free drug group or the orally delivered free drug group. ${ }^{46}$ Rivastigmine-loaded liposomes were administered orally and intraperitoneally in an AD animal model, and the results showed the highest $\mathrm{AChE}$ inhibition with the use of rivastigmine-sodium taurocholate liposomes. ${ }^{47}$

The transport of rivastigmine-containing liposomes across Caco- 2 cells has also been studied. The highest cumulative amount of rivastigmine to pass through the Caco- 2 cell cultures was found for the rivastigmine-sodium taurocholate solution compared to the rivastigmine-sodium taurocholate liposome. Rivastigmine liposomes and molecular solutions were also administered to animals and the AChE activity calculated using blood and brain tissue samples, and the highest value of AChE inhibition was observed for the rivastigmine and sodium taurocholate liposomes. ${ }^{48}$

Folic acid niosomes were prepared using different nonionic surfactants and cholesterol via the lipid hydration technique, and ex vivo perfusion studies were performed using a rat model. The drug was found to be absorbed through the nasal cavity at the end of 6 hours. ${ }^{49}$ Folic acid has been associated with an improvement in the response of cholinesterase inhibitors in people with AD. ${ }^{284}$

Freeze-dried niosomes loaded with $G$. biloba extract were developed with improved oral bioavailability. The in vivo distribution of $\mathrm{GbE}$ niosomes in the rat showed that the flavonoid glycoside biomarker content in the brain was significantly higher for the niosome group than for the G. biloba extract tablet group. ${ }^{51}$ Change in pharmacokinetic behavior, in vivo distribution, and higher accumulation in the brain with the use of the plant drug extract or AChE inhibitor drugs indicate the pharmacotherapeutic uses of niosomes in diseases affecting the brain. Phytosomes containing G. biloba were administered to rats via the oral route. Compared to a sodium nitrite treatment, these phytosomes were able to increase the activities of antioxidant enzymes in all the brain regions. ${ }^{50}$ However, many of the early trials used unsatisfactory methods, were small, and publication bias cannot be excluded. The evidence that G. biloba has predictable and clinically significant benefit for people with dementia or cognitive impairment is inconsistent and unreliable. ${ }^{285}$

\section{Surfactant-based systems}

Surfactant-based drug delivery systems are different drug delivery systems in which surfactant molecules are 
self-aggregated, usually in the presence of water, to form structures with variable parameters depending on the concentration of the surfactant, the presence of salts, or the temperature. These aggregates become more organized even when oils or other components such as other surfactants are added to the surfactant-water system. ${ }^{286}$ Thus, MEs, nanoemulsions (NEs), and lyotropic LC mesophases with different geometries can be generated. ${ }^{28,287}$

MEs are usually thermodynamically stable isotropic liquids formed by mixing oil, water, and surfactants together. NEs, by contrast, are conventional emulsions that contain very small particles. The droplet sizes of MEs are between 10 and $140 \mathrm{~nm},{ }^{288}$ which results in optically transparent and thermodynamically stable systems. ${ }^{289,290}$ NEs are up to $140 \mathrm{~nm}$ in diameter and are not transparent and less thermodynamically stable than MEs (Figure 5) ${ }^{290}$ The two systems are very different because NEs are formed by mechanical shearing and ME phases are formed by self-assembly. ${ }^{291}$

Other parameters can distinguish MEs from NEs: MEs are more stable in long-term storage than NEs; MEs can be agitated, cooled, or heated and then returned to their original conditions, whereas NEs cannot return to their original conditions; MEs have a homogeneous droplet size while NEs have a range of heterogeneously sized droplets; and MEs may or may not contain spherical droplets due to the lower interfacial tension while NEs consist of spherical droplets due to the large Laplace pressure acting upon them. ${ }^{290}$

MEs are formed from spontaneous mixtures of oils, water, and surfactants, ${ }^{292,293}$ though it is often necessary to apply stirring or heating ${ }^{292,294}$ to facilitate the formation of MEs due to kinetic energy barriers that must be overcome or mass transport limitations that inhibit their spontaneous formation. ${ }^{290} \mathrm{NEs}$ are formed using the input of some external energy provided by high-pressure homogenizers, ${ }^{295-297}$ microfluidizers, ${ }^{298}$ and sonication methods ${ }^{299}$ to convert the mixture into a colloidal dispersion or phase inversion. Spontaneous emulsification methods ${ }^{296}$ can then be used to form NEs.

NEs containing curcumin were developed for intranasal delivery, and the results from behavioral experiments showed improved memory and learning in the group treated with curcumin-loaded NEs compared with the group treated with the pure drug. ${ }^{300}$ MEs were developed for transdermal delivery in order to manage $\mathrm{AD}$, and mice given MEs containing huperzine A showed improved cognitive functions compared to mice given the drug in suspension via the oral route..$^{35} \mathrm{An}$ ME-based patch for the transdermal delivery of huperzine A and ligustrazine phosphate was developed, and the results showed that, unlike the monotherapy, the combined therapy had a synergistic effect against amnesia induced in mice by 9 days after administration. ${ }^{301}$

The intranasal administration of $\beta$-asarone-loaded MEs resulted in a ratio of $\mathrm{AUC}_{\text {brain }} / \mathrm{AUC}_{\text {plasma }}$ that was significantly higher compared to intravenous administration. ${ }^{52}$ Another study was developed, in which an anticholinesterase alkaloidal extract from Tabernaemontana divaricata was loaded into MEs. The results showed a good stability of the MEs and an AChE activity of more than $80 \%$ by 180 days. Moreover, the skin permeation and retention of the formulation increased within 24 hours after transdermal delivery of the extract..$^{53}$

Tacrine-loaded MEs showed a rapid absorption and nose-to-brain transmission that was twofold higher than that of an intranasally administered drug solution. A larger amount of tacrine was transported into the brains of scopolamine-induced amnesic mice after the intranasal

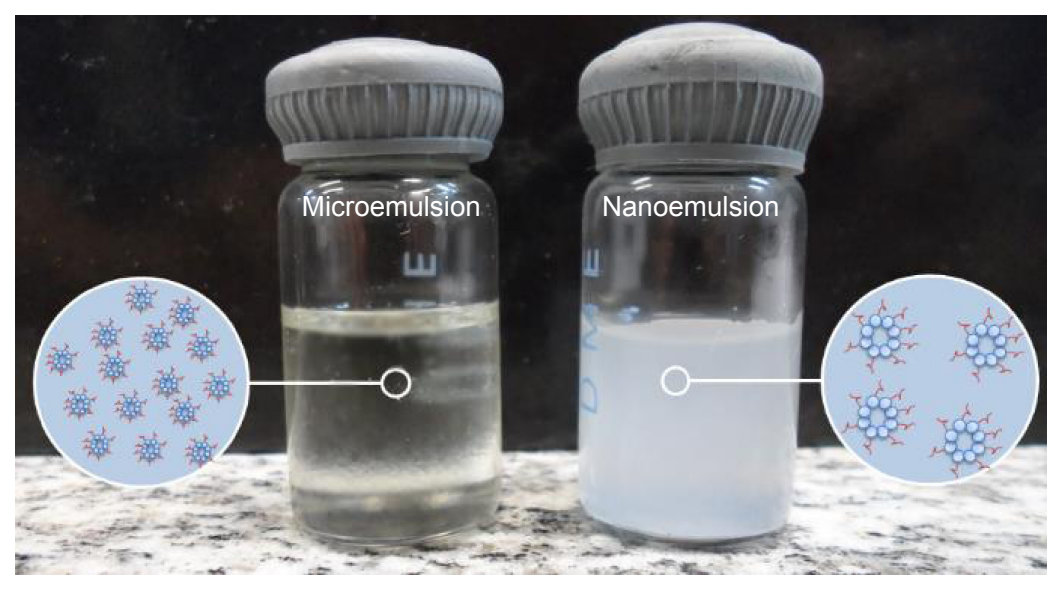

Figure 5 Photograph of microemulsion and nanoemulsion.

Note: Enlarged areas show schematics of the size of droplets formed. 

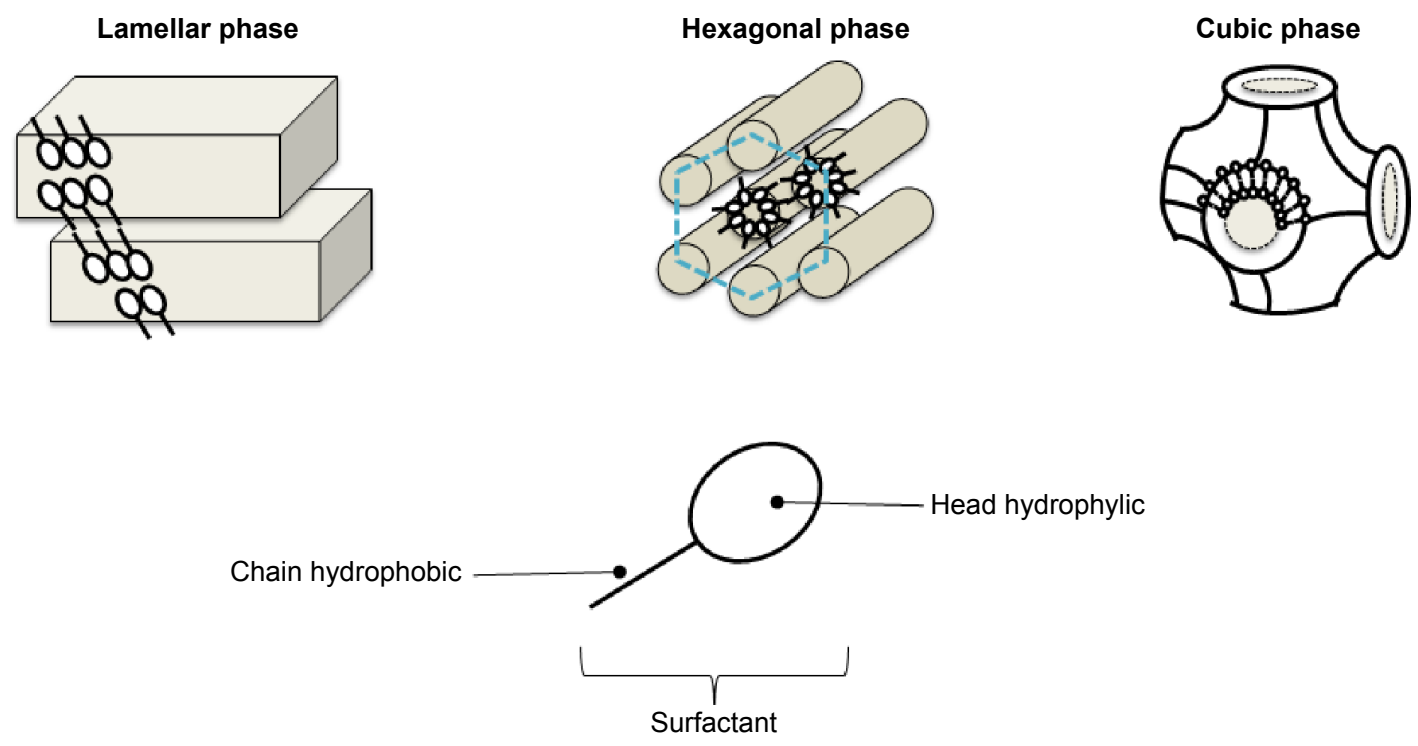

Figure 6 Schematic representation of lamellar, hexagonal, and cubic liquid crystal mesophases formed by surfactant molecules' self-assembly.

administration of tacrine-loaded MEs. These mice also showed the fastest recovery of memory loss. ${ }^{54}$

LCs consist of matter in a state with properties between those of conventional liquids and those of solid crystals. ${ }^{302}$ In other words, LCs have the structural behavior and rigidity of a solid combined with the mobility, disorder, and fluidity of an isotropic liquid. ${ }^{303}$ Lyotropic mesophases can be considered to be micelles with ordered molecular arrangements characterized by alternating hydrophobic and hydrophilic regions. ${ }^{304}$ By increasing the concentration of surfactants, lamellar, hexagonal, and cubic liquid-crystalline forms can be generated (Figure 6). ${ }^{305}$

The lamellar phase is formed from bilayers separated by layers of surfactants and solvents, which forms a one- or two-dimensional network. ${ }^{306}$ In the hexagonal phase, the aggregates are formed by the arrangement of long cylinders that form two- or three-dimensional structures. ${ }^{307}$ Lyotropic cubic phases have more complicated structures consisting of a curved, bicontinuous lipid bilayer that extends in three dimensions to generate two interpene trating, but noncontacting, aqueous nanochannels. ${ }^{308,309}$

Self-assembly systems display phase transformations and notable in situ thickening after administration. These systems are also of interest in relation to drug delivery to the body cavities. ${ }^{305}$ The intranasal administration of LCs can be interesting due to the dilution of LCs in nasal fluid, which promotes the phase transition to a hexagonal or cubic LC that can prolong the residence time of the formulation in contact with the mucosa. ${ }^{310}$ In the case of LC phases, the mechanism of mucoadhesion most likely involves the rheological properties of the system, which are similar to those of in situ gelling vehicles. ${ }^{311}$ Due to their high viscosity, hexagonal and cubic phases have been suggested as mucoadhesives. However, the viscosity of cubic phases can hinder their nasal administration. To circumvent this handling problem, precursor formulations of liquid-crystalline mesophases have been proposed. ${ }^{312}$ Numerous studies have shown that MEs and lamellar phase can be used as a precursor of the hexagonal or cubic phases ${ }^{310,311,313-317}$ after the stimuli in situ.

LC systems significantly increased the transdermal delivery of the $T$. divaricata extract at 24 hours. When loaded into an LC system, an alkaloidal extract from the $T$. divaricata stem may act as an alternative percutaneous formulation for enhancing the acetylcholine level in patients with $\mathrm{AD} .^{53}$

The nasal administration of LCs in the treatment and management of $\mathrm{AD}$ is a tool that has been unexplored by researchers. LCs have been shown to be an optimal system for intranasal administration; in situ gelation occurs by dilution by nasal fluid and results in increased residence time in the nasal cavity and targeting of drugs to the brain.

\section{Remarks and challenges}

Approximately 15 million people worldwide are currently afflicted by $\mathrm{AD} .^{3}$ This number is expected to increase fourfold by $2050 .{ }^{3}$ Nanotechnology offers the potential for designing drug delivery systems with many properties. In the context of treating $\mathrm{AD}$, these types of nanosystems could efficiently carry and deliver drugs and other neuroprotective molecules to the brain., ${ }^{4,318,319}$ The intranasal route plays a role in overcoming the BBB and targeting the drugs directly to the brain. ${ }^{282,319-325}$ However, the oral, dermal, and intravenous routes can be used to administration of nanodevices 
to target to the brain passing by $\mathrm{BBB}^{276,326-329}$ to enhanced bioavailability, pharmacodynamic properties, and decreased adverse effects of these drugs to maximize pharmacotherapy in patients with $\mathrm{AD}$.

Though the registry of patents for nanotechnologybased products is currently increasing, ${ }^{323,330,331}$ clinical trials are needed to evaluate their clinical efficacy and potential toxicological effects to human health. ${ }^{332}$ In the near future, neurologists and patients will benefit from suitable nanotechnology-based drug delivery systems that could lead to improved therapeutic outcomes with reduced costs. Although there are no clinical studies on the use of nanotechnology to treat $\mathrm{AD}$, nanotechnology is also predicted to alter health care in neurology, providing novel methods for identifying $\mathrm{AD}^{19}$ and customizing a patient's therapeutic profile.

\section{Acknowledgments}

The authors are grateful to the São Paulo Research Foundation (FAPESP) (São Paulo, Brazil, Coordination for the Improvement of Higher Education Personnel (CAPES) (Brasília, Brazil) for research fellowships and Programa de Apoio ao Desenvolvimento Científico (PADC-FCF-UNESP) for financial support.

\section{Author contributions}

BFS made substantial contributions in conceiving this review, searching the bibliographical data, conducting the analysis, and critically revising it for important intellectual content. MPDG and MC conducted the analysis and revised it critically for important intellectual content. All authors gave final approval of the version to be published.

\section{Disclosure}

The authors report no conflicts of interest in this work.

\section{References}

1. Dubois B, Feldman HH, Jacova C, etal. Revising the definition of Alzheimer's disease: a new lexicon. Lancet Neurol. 2010;9(11):1118-1127.

2. Querfurth HW, LaFerla FM. Alzheimer's disease. N Engl J Med. 2010; 362(4):329-344.

3. Alzheimer's Association. 2013 Alzheimer's disease facts and figures. Alzheimers Dement. 2013;9(2):208-245.

4. Sood S, Jain K, Gowthamarajan K. Intranasal therapeutic strategies for management of Alzheimer's disease. J Drug Target. 2014; 22(4):279-294.

5. Mehta M, Adem A, Sabbagh M. New acetylcholinesterase inhibitors for Alzheimer's disease. Int J Alzheimers Dis. 2012;2012:728983.

6. Colović MB, Krstić DZ, Lazarević-Pašti TD, Bondžić AM, Vasić VM. Acetylcholinesterase inhibitors: pharmacology and toxicology. Curr Neuropharmacol. 2013;11(3):315-335.

7. Jann MW, Shirley KL, Small GW. Clinical pharmacokinetics and pharmacodynamics of cholinesterase inhibitors. Clin Pharmacokinet. 2002;41(10):719-739.
8. Watkins PB, Zimmerman HJ, Knapp MJ, Gracon SI, Lewis KW. Hepatotoxic effects of tacrine administration in patients with Alzheimer's disease. JAMA. 1994;271(13):992-998.

9. Raina P, Santaguida P, Ismaila A, et al. Effectiveness of cholinesterase inhibitors and memantine for treating dementia: evidence review for a clinical practice guideline. Ann Intern Med. 2008;148(5): 379-397.

10. Periclou A, Ventura D, Rao N, Abramowitz W. Pharmacokinetic study of memantine in healthy and renally impaired subjects. Clin Pharmacol Ther. 2006;79(1):134-143.

11. Kornhuber J, Kennepohl EM, Bleich S, et al. Memantine pharmacotherapy: a naturalistic study using a population pharmacokinetic approach. Clin Pharmacokinet. 2007;46(7):599-612.

12. Arias JL, editor. Key aspects in nanotechnology and drug delivery. In: Nanotechnology and Drug Delivery. Volume 1: Nanoplatforms in Drug Delivery. Boca Raton: CRC Press; 2015:1-27.

13. Sharma S, Singh A. Nanotechnology based targeted drug delivery: current status and future prospects for drug development, drug discovery and development. In: Kapetanović IM, editor. Drug Discovery and Development: Present and Future. Croatia: InTech; 2011: $427-462$.

14. Suri K, Wolfram J, Shen H, Ferrari M. Advances in nanotechnologybased drug delivery platforms and novel drug delivery systems. In: Singh M, Salnikova M, editors. Novel Approaches and Strategies for Biologics, Vaccines and Cancer Therapies. San Diego: Academic Press; 2015:41-58.

15. Parveen S, Sahoo S. Nanomedicine: clinical applications of polyethylene glycol conjugated proteins and drugs. Clin Pharmacokinet. 2006;45(10):965-988.

16. Orive G, Hernández RM, Rodríguez Gascón A, Domínguez-Gil A, Pedraz JL. Drug delivery in biotechnology: present and future. Curr Opin Biotechnol. 2003;14(6):659-664.

17. Safari J, Zarnegar Z. Advanced drug delivery systems: nanotechnology of health design A review. Journal of Saudi Chemical Society. 2014; 18(2):85-99.

18. Betancourt T, Doiron A, Homan KA, Brannon-Peppas L. Controlled release and nanotechnology. In: de Villiers MM, Aramwit P, Kwon GS, editors. Nanotechnology in Drug Delivery. New York: Springer; 2009:283-312.

19. Brambilla D, Le Droumaguet B, Nicolas J, et al. Nanotechnologies for Alzheimer's disease: diagnosis, therapy, and safety issues. Nanomedicine. 2011;7(5):521-540.

20. Nazem A, Mansoori GA. Nanotechnology solutions for Alzheimer's disease: advances in research tools, diagnostic methods and therapeutic agents. J Alzheimers Dis. 2008;13(2):199-223.

21. Wilson B, Samanta MK, Santhi K, Kumar KP, Paramakrishnan N, Suresh B. Targeted delivery of tacrine into the brain with polysorbate 80 -coated poly(n-butylcyanoacrylate) nanoparticles. Eur J Pharm Biopharm. 2008;70(1):75-84.

22. Wilson B, Samanta MK, Santhi K, Kumar KP, Paramakrishnan N, Suresh B. Poly(n-butylcyanoacrylate) nanoparticles coated with polysorbate 80 for the targeted delivery of rivastigmine into the brain to treat Alzheimer's disease. Brain Res. 2008;1200:159-168.

23. Zhang C, Wan X, Zheng X, et al. Dual-functional nanoparticles targeting amyloid plaques in the brains of Alzheimer's disease mice. Biomaterials. 2014;35(1):456-465.

24. Zhang C, Chen J, Feng C, et al. Intranasal nanoparticles of basic fibroblast growth factor for brain delivery to treat Alzheimer's disease. Int J Pharm. 2014;461(1-2):192-202.

25. Brambilla D, Verpillot R, De Kimpe L, Taverna M, Le Droumaguet B, Andrieux K. Nanoparticles against Alzheimer's disease: PEG-PACA nanoparticles are able to link the $\mathrm{A} \beta$-peptide and influence its aggregation kinetic. J Biotechnol. 2010;150 Suppl:27.

26. Brambilla D, Verpillot R, Taverna M, et al. New method based on capillary electrophoresis with laser-induced fluorescence detection (CE-LIF) to monitor interaction between nanoparticles and the amyloid- $\beta$ peptide. Anal Chem. 2010;82(24):10083-10089. 
27. Joshi SA, Chavhan SS, Sawant KK. Rivastigmine-loaded PLGA and PBCA nanoparticles: preparation, optimization, characterization, in vitro and pharmacodynamic studies. Eur J Pharm Biopharm. 2010;76(2):189-199.

28. Fazil M, Md S, Haque S, et al. Development and evaluation of rivastigmine loaded chitosan nanoparticles for brain targeting. Eur J Pharm Sci. 2012;47(1):6-15.

29. Amorim Cde M, Couto AG, Netz DJ, de Freitas RA, Bresolin TM. Antioxidant idebenone-loaded nanoparticles based on chitosan and N-carboxymethylchitosan. Nanomedicine. 2010;6(6):745-752.

30. Yusuf M, Khan M, Khan RA, Ahmed B. Preparation, characterization, in vivo and biochemical evaluation of brain targeted Piperine solid lipid nanoparticles in an experimentally induced Alzheimer's disease model. J Drug Target. 2013;21(3):300-311.

31. Sood S, Jain K, Gowthamarajan K. Curcumin-donepezil-loaded nanostructured lipid carriers for intranasal delivery in an Alzheimer's disease model. Alzheimers Dement. 2013;9(4):P299.

32. Zhuang CY, Li N, Wang M, et al. Preparation and characterization of vinpocetine loaded nanostructured lipid carriers (NLC) for improved oral bioavailability. Int J Pharm. 2010;394(1-2):179-185.

33. Frozza RL, Salbego C, Bernardi A, et al. Incorporation of resveratrol into lipid-core nanocapsules improves its cerebral bioavailability and reduces the A $\beta$-induced toxicity. Alzheimers Dement. 2011;7(4):S114.

34. Bondì ML, Craparo EF, Giammona G, Drago F. Brain-targeted solid lipid nanoparticles containing riluzole: preparation, characterization and biodistribution. Nanomedicine (Lond). 2009;5(1):25-32.

35. Patel PA, Patil SC, Kalaria DR, Kalia YN, Patravale VB. Comparative in vitro and in vivo evaluation of lipid based nanocarriers of Huperzine $\mathrm{A}$. Int J Pharm. 2013;446(1-2):16-23.

36. Kakkar V, Muppu SK, Chopra K, Kaur IP. Curcumin loaded solid lipid nanoparticles: an efficient formulation approach for cerebral ischemic reperfusion injury in rats. Eur J Pharm Biopharm. 2013;85 (3 Pt A):339-345.

37. Yang ZZ, Zhang YQ, Wang ZZ, Wu K, Lou JN, Qi XR. Enhanced brain distribution and pharmacodynamics of rivastigmine by liposomes following intranasal administration. Int J Pharm. 2013;452(1-2): 344-354.

38. Ismail MF, Elmeshad AN, Salem NA. Potential therapeutic effect of nanobased formulation of rivastigmine on rat model of Alzheimer's disease. Int J Nanomedicine. 2013;8:393-406.

39. Kumaraswamy P, Sethuraman S, Krishnan UM. Liposomal delivery of a beta sheet blocker peptide for the treatment of Alzheimer's disease. Alzheimers Dement. 2012;8(4 Suppl):P705.

40. Sancini G, Gregori M, Salvati E, et al. Functionalization with TATpeptide enhances blood-brain barrier crossing in vitro of nanoliposomes carrying a curcumin-derivative to bind amyloid- $\beta$ peptide. $J$ Nanomed Nanotechnol. 2013;4(3).

41. Markoutsa E, Papadia K, Giannou AD, et al. Mono and dually decorated nanoliposomes for brain targeting, in vitro and in vivo studies. Pharm Res. 2014;31(5):1275-1289.

42. Mourtas S, Lazar AN, Markoutsa E, Duyckaerts C, Antimisiaris SG. Multifunctional nanoliposomes with curcumin-lipid derivative and brain targeting functionality with potential applications for Alzheimer disease. Eur J Med Chem. 2014;80:175-183.

43. Lazar AN, Mourtas S, Youssef I, et al. Curcumin-conjugated nanoliposomes with high affinity for $A \beta$ deposits: possible applications to Alzheimer disease. Nanomedicine. 2013;9(5):712-721.

44. Mourtas S, Canovi M, Zona C, et al. Curcumin-decorated nanoliposomes with very high affinity for amyloid- $\beta 1-42$ peptide. Biomaterials. 2011;32(6):1635-1645.

45. Mufamadi MS, Choonara YE, Kumar P, et al. Ligand-functionalized nanoliposomes for targeted delivery of galantamine. Int $J$ Pharm. 2013;448(1):267-281.

46. Arumugam K, Subramanian GS, Mallayasamy SR, Averineni RK, Reddy MS, Udupa N. A study of rivastigmine liposomes for delivery into the brain through intranasal route. Acta Pharm. 2008; 8(3):287-297.
47. Mutlu NB, Değim Z, Yılmaz Ş, Eşsiz D, Nacar A. New perspective for the treatment of Alzheimer diseases: liposomal rivastigmine formulations. Drug Dev Ind Pharm. 2011;37(7):775-789.

48. Degim Z, Mutlu NB, Yilmaz S, Eşsiz D, Nacar A. Investigation of liposome formulation effects on rivastigmine transport through human colonic adenocarcinoma cell line (CACO-2). Pharmazie. 2010;65(1):32-40.

49. Ravouru N, Kondreddy P, Korakanchi D, Haritha M. Formulation and evaluation of niosomal nasal drug delivery system of folic acid for brain targeting. Curr Drug Discov Technol. 2013;10(4):270-282.

50. Naik SR, Pilgaonkar VW, Panda VS. Evaluation of antioxidant activity of Ginkgo biloba phytosomes in rat brain. Phytother Res. 2006; 20(11):1013-1016.

51. Jin Y, Wen J, Garg S, et al. Development of a novel niosomal system for oral delivery of Ginkgo biloba extract. Int J Nanomedicine. 2013;8:421-430.

52. Zhang LK, Xu RX, Jiang M, et al. Evaluation of brain-targeting of $\beta$-asarone microemulsion by intranasal administration. Chinese Traditional and Herbal Drugs. 2014;45(1):86-89.

53. Chaiyana W, Rades T, Okonogi S. Characterization and in vitro permeation study of microemulsions and liquid crystalline systems containing the anticholinesterase alkaloidal extract from Tabernaemontana divaricata. Int J Pharm. 2013;452(1-2):201-210.

54. Jogani VV, Shah PJ, Mishra P, Mishra AK, Misra AR. Intranasal mucoadhesive microemulsion of tacrine to improve brain targeting. Alzheimer Dis Assoc Disord. 2008;22(2):116-124.

55. Selkoe DJ. Alzheimer's disease: genes, proteins, and therapy. Physiol Rev. 2001;81(2):741-766.

56. Hardy J, Selkoe DJ. The amyloid hypothesis of Alzheimer's disease: progress and problems on the road to therapeutics. Science. 2002; 297(5580):353-356.

57. Finder VH, Glockshuber R. Amyloid-beta aggregation. Neurodegener Dis. 2007;4(1):13-27.

58. Mattson MP. Pathways towards and away from Alzheimer's disease. Nature. 2004;430(7000):631-639.

59. Bush AI. The metal theory of Alzheimer's disease. J Alzheimers Dis. 2013;33 Suppl 1:S277-S281.

60. Gouras GK, Beal MF. Metal chelator decreases Alzheimer $\beta$-amyloid plaques. Neuron. 2001;30(3):641-642.

61. Huang X, Cuajungco MP, Atwood CS, et al. $\mathrm{Cu}(\mathrm{II})$ potentiation of alzheimer abeta neurotoxicity. Correlation with cell-free hydrogen peroxide production and metal reduction. J Biol Chem. 1999; 274(52):37111-37116.

62. Lovell MA, Robertson JD, Teesdale WJ, Campbell JL, Markesbery WR. Copper, iron and zinc in Alzheimer's disease senile plaques. J Neurol Sci. 1998;158(1):47-52.

63. Cherny RA, Legg JT, McLean CA, et al. Aqueous dissolution of Alzheimer's disease Abeta amyloid deposits by biometal depletion. J Biol Chem. 1999;274(33):23223-23228.

64. Cherny RA, Atwood CS, Xilinas ME, et al. Treatment with a copper-zinc chelator markedly and rapidly inhibits beta-amyloid accumulation in Alzheimer's disease transgenic mice. Neuron. 2001;30(3):665-676.

65. Bartus RT, Emerich DF. Cholinergic markers in Alzheimer disease. JAMA. 1999;282(23):2208-2209.

66. Rossor MN, Emson PC, Mountjoy CQ, Roth M, Iversen LL. Reduced amounts of immunoreactive somatostatin in the temporal cortex in senile dementia of Alzheimer type. Neurosci Lett. 1980;20(3):373-377.

67. Henke H, Lang W. Cholinergic enzymes in neocortex, hippocampus and basal forebrain of non-neurological and senile dementia of Alzheimertype patients. Brain Res. 1983;267(2):281-291.

68. Soininen H, Kosunen O, Helisalmi S, et al. A severe loss of choline acetyltransferase in the frontal cortex of Alzheimer patients carrying apolipoprotein epsilon 4 allele. Neurosci Lett. 1995;187(2): $79-82$.

69. Gattaz WF, Forlenza OV, Talib LL, Barbosa NR, Bottino CMC. Platelet phospholipase A2 activity in Alzheimer's disease and mild cognitive impairment. J Neural Transm. 2004;111(5):591-601. 
70. Gattaz WF, Talib LL, Schaeffer EL, Diniz BS, Forlenza OV. Low platelet iPLA $\mathrm{A}_{2}$ activity predicts conversion from mild cognitive impairment to Alzheimer's disease: a 4-year follow-up study. J Neural Transm. 2014;121(2):193-200.

71. Gattaz WF, Cairns NJ, Levy R, Förstl H, Braus DF, Maras A. Decreased phospholipase A2 activity in the brain and in platelets of patients with Alzheimer's disease. Eur Arch Psychiatry Clin Nuerosci. 1996;246(3):129-131.

72. Weingarten MD, Lockwood AH, Hwo SY, Kirschner MW. A protein factor essential for microtubule assembly. Proc Natl Acad Sci U S A. 1975;72(5):1858-1862.

73. Gong CX, Grundke-Iqbal I, Iqbal K. Targeting tau protein in Alzheimer's disease. Drugs Aging. 2010;27(5):351-365.

74. Ballatore C, Lee VM, Trojanowski JQ. Tau-mediated neurodegeneration in Alzheimer's disease and related disorders. Nat Rev Neurosci. 2007;8(9):663-672.

75. McGeer PL, McGeer EG. The inflammatory response system of brain: implications for therapy of Alzheimer and other neurodegenerative diseases. Brain Res Brain Res Rev. 1995;21(2):195-218.

76. Blasko I, Stampfer-Kountchev M, RobatscherP, Veerhuis R, EikelenboomP, Grubeck-Loebenstein B. How chronic inflammation can affect the brain and support the development of Alzheimer's disease in old age: the role of microglia and astrocytes. Aging Cell. 2004;3(4):169-176.

77. Mrak RE, Griffin WS. Interleukin-1, neuroinflammation, and Alzheimer's disease. Neurobiol Aging. 2001;22(6):903-908.

78. Johnstone M, Gearing AJ, Miller KM. A central role for astrocytes in the inflammatory response to beta-amyloid; chemokines, cytokines and reactive oxygen species are produced. $J$ Neuroimmunol. 1999;93(1-2):182-193.

79. Tuppo EE, Arias HR. The role of inflammation in Alzheimer's disease. Int J Biochem Cell Biol. 2005;37(2):289-305.

80. Li C, Zhao R, Gao K, et al. Astrocytes: implications for neuroinflammatory pathogenesis of Alzheimer's disease. Curr Alzheimer Res. 2011;8(1):67-80.

81. Brown GC, Bal-Price A. Inflammatory neurodegeneration mediated by nitric oxide, glutamate, and mitochondria. Mol Neurobiol. 2003; 27(3):325-355.

82. Rogers J, Lue LF. Microglial chemotaxis, activation, and phagocytosis of amyloid beta-peptide as linked phenomena in Alzheimer's disease Neurochem Int. 2001;39(5-6):333-340.

83. Sperling RA, Aisen PS, Beckett LA, et al. Toward defining the preclinical stages of Alzheimer's disease: recommendations from the National Institute on Aging-Alzheimer's Association workgroups on diagnostic guidelines for Alzheimer's disease. Alzheimers Dement. 2011;7(3):280-292.

84. McKhann GM, Knopman DS, Chertkow H, et al. The diagnosis of dementia due to Alzheimer's disease: recommendations from the National Institute on Aging-Alzheimer's Association workgroups on diagnostic guidelines for Alzheimer's disease. Alzheimers Dement. 2011;7(3):263-269.

85. Albert MS, DeKosky ST, Dickson D, et al. The diagnosis of mild cognitive impairment due to Alzheimer's disease: recommendations from the National Institute on Aging-Alzheimer's Association workgroups on diagnostic guidelines for Alzheimer's disease. Alzheimers Dement 2011;7(3):270-279.

86. Jack CR Jr, Albert MS, Knopman DS, et al. Introduction to the recommendations from the National Institute on Aging-Alzheimer's Association workgroups on diagnostic guidelines for Alzheimer's disease. Alzheimers Dement. 2011;7(3):257-262.

87. Teng E, Ringman JM, Ross LK, et al; Alzheimer's Disease Research Centers of California-Depression in Alzheimer's Disease Investigators. Diagnosing depression in Alzheimer disease with the national institute of mental health provisional criteria. Am J Geriatr Psychiatry. 2008;16(6):469-477.

88. Olin JT, Schneider LS, Katz IR, et al. Provisional diagnostic criteria for depression of Alzheimer disease. Am J Geriatr Psychiatry. 2002; 10(2):125-128.
89. Knopman DS, DeKosky ST, Cummings JL, et al. Practice parameter: diagnosis of dementia (an evidence-based review). Report of the Quality Standards Subcommittee of the American Academy of Neurology. Neurology. 2001;56(9):1143-1153.

90. Jagust WJ, Budinger TF, Reed BR. The diagnosis of dementia with single photon emission computed tomography. Arch Neurol. 1987; 44(3):258-262.

91. Bird JM, Levy R, Jacoby RJ. Computed tomography in the elderly: changes over time in a normal population. Br J Psychiatry. 1986; 148:80-85.

92. Luxenberg JS, Haxby JV, Creasey H, Sundaram M, Rapoport SI Rate of ventricular enlargement in dementia of the Alzheimer type correlates with rate of neuropsychological deterioration. Neurology. 1987;37(7):1135-1140.

93. Killiany RJ, Gomez-Isla T, Moss M, et al. Use of structural magnetic resonance imaging to predict who will get Alzheimer's disease. Ann Neurol. 2000;47(4):430-439.

94. Killiany RJ, Hyman BT, Gomez-Isla T, et al. MRI measures of entorhinal cortex vs hippocampus in preclinical AD. Neurology. 2002;58(8):1188-1196.

95. Marshall GA, Monserratt L, Harwood D, Mandelkern M, Cummings JL, Sultzer DL. Positron emission tomography metabolic correlates of apathy in Alzheimer disease. Arch Neurol. 2007;64(7):1015-1020.

96. Mosconi L, Berti V, Glodzik L, Pupi A, De Santi S, de Leon MJ. Pre-clinical detection of Alzheimer's disease using FDG-PET, with or without amyloid imaging. $J$ Alzheimers Dis. 2010;20(3): 843-854.

97. Minoshima S, Frey KA, Koeppe RA, Foster NL, Kuhl DE. A diagnostic approach in Alzheimer's disease using three-dimensional stereotactic surface projections of fluorine-18-FDG PET. J Nucl Med. 1995;36(7):1238-1248.

98. Edison P, Archer HA, Hinz R, et al. Amyloid, hypometabolism, and cognition in Alzheimer disease: an [11C]PIB and [18F]FDG PET study. Neurology. 2007;68(7):501-508.

99. Dukart J, Kherif F, Mueller K, et al; Alzheimer's Disease Neuroimaging Initiative. Generative FDG-PET and MRI model of aging and disease progression in Alzheimer's disease. PLoS Comput Biol. 2013;9(4):e1002987.

100. Choi SR, Schneider JA, Bennett DA, et al. Correlation of amyloid $P E T$ ligand florbetapir $F 18$ binding with $A \beta$ aggregation and neuritic plaque deposition in postmortem brain tissue. Alzheimer Dis Assoc Disord. 2012;26(1):8-16.

101. Clark CM, Schneider JA, Bedell BJ, et al; AV45-A07 Study Group. Use of florbetapir-PET for imaging beta-amyloid pathology. JAMA 2011;305(3):275-283.

102. Lister-James J, Pontecorvo MJ, Clark C, et al. Florbetapir f-18: a histopathologically validated beta-amyloid positron emission tomography imaging agent. Semin Nucl Med. 2011;41(4):300-304.

103. Johnson KA, Sperling RA, Gidicsin CM, et al; AV45-A11 study group. Florbetapir (F18-AV-45) PET to assess amyloid burden in Alzheimer's disease dementia, mild cognitive impairment, and normal aging. Alzheimers Dement. 2013;9(5 Suppl):S72-S83.

104. Vandenberghe R, Van Laere K, Ivanoiu A, et al. 18F-flutemetamol amyloid imaging in Alzheimer disease and mild cognitive impairment: a phase 2 trial. Ann Neurol. 2010;68(3):319-329.

105. Harvey RJ, Skelton-Robinson M, Rossor MN. The prevalence and causes of dementia in people under the age of 65 years. $J$ Neurol Neurosurg Psychiatry. 2003;74(9):1206-1209.

106. Osimani A, Berger A, Friedman J, Porat-Katz BS, Abarbanel JM. Neuropsychology of vitamin B12 deficiency in elderly dementia patients and control subjects. J Geriatr Psychiatry Neurol. 2005; 18(1):33-38.

107. Vargas AP, Carod-Artal FJ, Del Negro MC, Rodrigues MP. [Dementia caused by neurosyphilis: clinical and neuropsychological follow-up of a patient]. Arq Neuropsiquiatr. 2000;58(2B):578-582. Portuguese.

108. Fleming KC, Adams AC, Petersen RC. Dementia: diagnosis and evaluation. Mayo Clin Proc. 1995;70(11):1093-1107. 
109. Rasmussen KL, Tybjærg-Hansen A, NordestgaardBG, Frikke-SchmidtR. Apolipoprotein E plasma level and genotype - /INS; risk of dementia in 76,000 individuals from the general population. J Neurol Sci. 2013;333:e342.

110. Goldman JS, Hahn SE, Catania JW, et al; American College of Medical Genetics and the National Society of Genetic Counselors. Genetic counseling and testing for Alzheimer disease: joint practice guidelines of the American College of Medical Genetics and the National Society of Genetic Counselors. Genet Med. 2011;13(6):597-605.

111. KulkarniPV,RoneyCA,AntichPP,BonteFJ,RaghuAV,AminabhaviTM. Quinoline-n-butylcyanoacrylate-based nanoparticles for brain targeting for the diagnosis of Alzheimer's disease. Wiley Interdiscip Rev Nanomed Nanobiotechnol. 2010;2(1):35-47.

112. Härtig W, Paulke BR, Varga C, Seeger J, Harkany T, Kacza J. Electron microscopic analysis of nanoparticles delivering thioflavin-T after intrahippocampal injection in mouse: implications for targeting beta-amyloid in Alzheimer's disease. Neurosci Lett. 2003;338(2):174-176.

113. Massoud F, Léger GC. Pharmacological treatment of Alzheimer disease. Can J Psychiatry. 2011;56(10):579-588.

114. Winslow BT, Onysko MK, Stob CM, Hazlewood KA. Treatment of Alzheimer disease. Am Fam Physician. 2011;83(12):1403-1412.

115. Bentley P, Driver J, Dolan RJ. Modulation of fusiform cortex activity by cholinesterase inhibition predicts effects on subsequent memory. Brain. 2009;132(Pt 9):2356-2371.

116. Kavirajan H. Memantine: a comprehensive review of safety and efficacy. Expert Opin Drug Saf. 2009;8(1):89-109.

117. Lipton SA. The molecular basis of memantine action in Alzheimer's disease and other neurologic disorders: low-affinity, uncompetitive antagonism. Curr Alzheimer Res. 2005;2(2):155-165.

118. Mark LP, Prost RW, Ulmer JL, et al. Pictorial review of glutamate excitotoxicity: fundamental concepts for neuroimaging. AJNR Am J Neuroradiol. 2001;22(10):1813-1824.

119. Molinuevo JL, Lladó A, Rami L. Memantine: targeting glutamate excitotoxicity in Alzheimer's disease and other dementias. Am J Alzheimers Dis Other Demen. 2005;20(2):77-85.

120. Cacabelos R, Takeda M, Winblad B. The glutamatergic system and neurodegeneration in dementia: preventive strategies in Alzheimer's disease. Int J Geriatr Psychiatry. 1999;14(1):3-47.

121. Xia P, Chen HS, Zhang D, Lipton SA. Memantine preferentially blocks extrasynaptic over synaptic NMDA receptor currents in hippocampal autapses. $J$ Neurosci. 2010;30(33):11246-11250.

122. Rammes G, Danysz W, Parsons CG. Pharmacodynamics of memantine: an update. Curr Neuropharmacol. 2008;6(1):55-78.

123. Parsons CG, Stöffler A, Danysz W. Memantine: a NMDA receptor antagonist that improves memory by restoration of homeostasis in the glutamatergic system - too little activation is bad, too much is even worse. Neuropharmacology. 2007;53(6):699-723.

124. Srinivasan M, Lahiri DK. Significance of NF- $\kappa B$ as a pivotal therapeutic target in the neurodegenerative pathologies of Alzheimer's disease and multiple sclerosis. Expert Opin Ther Targets. 2015;19(4): 471-487.

125. Rubio-Perez JM, Morillas-Ruiz JM. A review: inflammatory process in Alzheimer's disease, role of cytokines. Scientific World Journal. 2012;2012:756357.

126. Wyss-Coray T, Rogers J. Inflammation in Alzheimer disease-a brief review of the basic science and clinical literature. Cold Spring Harb Perspect Med. 2012;2(1):a006346.

127. Alyautdin R, Khalin I, Nafeeza MI, Haron MH, Kuznetsov D. Nanoscale drug delivery systems and the blood-brain barrier. Int J Nanomedicine. 2014;9:795-811.

128. Haque S, Md S, Alam MI, Sahni JK, Ali J, Baboota S. Nanostructurebased drug delivery systems for brain targeting. Drug Dev Ind Pharm. 2012;38(4):387-411

129. Paolino D, Cosco D, Molinaro R, Celia C, Fresta M. Supramolecular devices to improve the treatment of brain diseases. Drug Discov Today. 2011;16(7-8):311-324.
130. Amidon GL, Lennernäs H, Shah VP, Crison JR. A theoretical basis for a biopharmaceutic drug classification: the correlation of in vitro drug product dissolution and in vivo bioavailability. Pharm Res. 1995;12(3):413-420.

131. Stegemann S, Leveiller F, Franchi D, de Jong H, Lindén H. When poor solubility becomes an issue: from early stage to proof of concept. Eur J Pharm Sci. 2007;31(5):249-261.

132. Oesterling BM, Gulati A, Joshi MD. Nanocarrier-based approaches for treatment and detection of Alzheimer's disease. J Nanosci Nanotechnol. 2014;14(1):137-156.

133. Patel MM, Goyal BR, Bhadada SV, Bhatt JS, Amin AF. Getting into the brain: approaches to enhance brain drug delivery. CNS Drugs. 2009;23(1):35-58

134. Sainsbury F, Zeng B, Middelberg APJ. Towards designer nanoemulsions for precision delivery of therapeutics. Curr Opin Chem Eng. 2014;4:11-17.

135. Aprahamian M, Michel C, Humbert W, Devissaguet JP, Damge C. Transmucosal passage of polyalkylcyanoacrylate nanocapsules as a new drug carrier in the small intestine. Biol Cell. 1987;61(1-2): 69-76.

136. Graff CL, Pollack GM. Nasal drug administration: potential for targeted central nervous system delivery. J Pharm Sci. 2005;94(6): 1187-1195.

137. Mathison S, Nagilla R, Kompella UB. Nasal route for direct delivery of solutes to the central nervous system: fact or fiction? J Drug Target. 1998;5(6):415-441.

138. Kreuter J. Nanoparticles and nanocapsules - new dosage forms in the nanometer size range. Pharm Acta Helv. 1978;53(2):33-39.

139. Guterres SS, Alves MP, Pohlmann AR. Polymeric nanoparticles, nanospheres and nanocapsules, for cutaneous applications. Drug Target Insights. 2007;2:147-157.

140. Couvreur P, Barratt G, Fattal E, Vauthier C. Nanocapsule technology: a review. 2002;19(2):36.

141. Boudad H, Legrand P, Lebas G, Cheron M, Duchêne D, Ponchel G. Combined hydroxypropyl-beta-cyclodextrin and poly(alkylcyanoacrylate) nanoparticles intended for oral administration of saquinavir. Int $J$ Pharm. 2001;218(1-2):113-124.

142. Souto EB, Severino P, Santana MHA. Preparação de nanopartículas poliméricas a partir da polimerização de monômeros: parte I [Preparation of polymeric nanoparticles by polymerization of monomers: part I]. Polímeros. 2012;22:96-100. Portuguese.

143. Dong Y, Ng WK, Shen S, Kim S, Tan RB. Scalable ionic gelation synthesis of chitosan nanoparticles for drug delivery in static mixers. Carbohydr Polym. 2013;94(2):940-945.

144. Arora S, Gupta S, Narang RK, Budhiraja RD. Amoxicillin loaded chitosan-alginate polyelectrolyte complex nanoparticles as mucopenetrating delivery system for H. pylori. Sci Pharm. 2011;79(3):673-694.

145. Mainardes RM, Evangelista RC. Praziquantel-loaded PLGA nanoparticles: preparation and characterization. J Microencapsul. 2005; 22(1): $13-24$

146. Mainardes RM, Evangelista RC. PLGA nanoparticles containing praziquantel: effect of formulation variables on size distribution. Int J Pharm. 2005;290(1-2):137-144.

147. Alshamsan A. Nanoprecipitation is more efficient than emulsion solvent evaporation method to encapsulate cucurbitacin I in PLGA nanoparticles. Saudi Pharm J. 2014;22(3):219-222.

148. Mainardes RM, Gremião MPD. Nanoencapsulation and characterization of zidovudine on poly(L-lactide) and poly(L-lactide)poly(ethylene glycol)-blend nanoparticles. J Nanosci Nanotechnol. 2012;12(11):8513-8521.

149. Calvo P, Remuñán-López C, Vila-Jato JL, Alonso MJ. Novel hydrophilic chitosan-polyethylene oxide nanoparticles as protein carriers. J Appl Polym Sci. 1997;63(1):125-132.

150. Murakami H, Kobayashi M, Takeuchi H, Kawashima Y. Preparation of poly(dl-lactide-co-glycolide) nanoparticles by modified spontaneous emulsification solvent diffusion method. Int $J$ Pharm. 1999;187(2):143-152. 
151. Mazzarino L, Coche-Guérente L, Labbé P, Lemos-Senna E, Borsali R. On the mucoadhesive properties of chitosan-coated polycaprolactone nanoparticles loaded with curcumin using quartz crystal microbalance with dissipation monitoring. J Biomed Nanotechnol. 2014;10(5):787-794.

152. Bilati U, Allémann E, Doelker E. Development of a nanoprecipitation method intended for the entrapment of hydrophilic drugs into nanoparticles. Eur J Pharm Sci. 2005;24(1):67-75.

153. Ali ME, Lamprecht A. Spray freeze drying for dry powder inhalation of nanoparticles. Eur J Pharm Biopharm. 2014;87(3):510-517.

154. Hu X, Guo Y, Wang L, Hua D, Hong Y, Li J. Coenzyme $Q_{10}$ nanoparticles prepared by a supercritical fluid-based method. J Supercrit Fluids. 2011;57(1):66-72.

155. Chu KS, Hasan W, Rawal S, et al. Plasma, tumor and tissue pharmacokinetics of Docetaxel delivered via nanoparticles of different sizes and shapes in mice bearing SKOV-3 human ovarian carcinoma xenograft. Nanomedicine. 2013;9(5):686-693.

156. Galloway AL, Murphy A, DeSimone JM, et al. Development of a nanoparticle-based influenza vaccine using the PRINT technology. Nanomedicine. 2013;9(4):523-531.

157. Gratton SE, Pohlhaus PD, Lee J, Guo J, Cho MJ, Desimone JM. Nanofabricated particles for engineered drug therapies: a preliminary biodistribution study of PRINT nanoparticles. J Control Release. 2007;121(1-2):10-18.

158. Jain KK. Nanobiotechnology-based drug delivery to the central nervous system. Neurodegener Dis. 2007;4(4):287-291.

159. Wohlfart S, Gelperina S, Kreuter J. Transport of drugs across the blood-brain barrier by nanoparticles. J Control Release. 2012;161(2): 264-273.

160. Barbu E, Molnàr E, Tsibouklis J, Górecki DC. The potential for nanoparticle-based drug delivery to the brain: overcoming the bloodbrain barrier. Expert Opin Drug Deliv. 2009;6(6):553-565.

161. Gao K, Jiang X. Influence of particle size on transport of methotrexate across blood-brain barrier by polysorbate 80 -coated polybutylcyanoacrylate nanoparticles. Int J Pharm. 2006;310(1-2):213-219.

162. Soni S, Babbar AK, Sharma RK, Banerjee T, Maitra A. Pharmacoscintigraphic evaluation of polysorbate 80 -coated chitosan nanoparticles for brain targeting. American Journal of Drug Delivery. 2005;3(3):205-212.

163. Jain KK. Nanoneurology. In: Applications of Biotechnology in Neurology. New York: Humana Press; 2013:283-294.

164. Zhang B, Sun X, Mei H, et al. LDLR-mediated peptide-22-conjugated nanoparticles for dual-targeting therapy of brain glioma. Biomaterials 2013;34(36):9171-9182.

165. Kuo YC, Hong TY. Delivering etoposide to the brain using catanionic solid lipid nanoparticles with surface 5-HT-moduline. Int J Pharm. 2014;465(1-2):132-142.

166. Zensi A, Begley D, Pontikis C, et al. Albumin nanoparticles targeted with Apo E enter the CNS by transcytosis and are delivered to neurones. J Control Release. 2009;137(1):78-86.

167. Xin H, Sha X, Jiang X, et al. The brain targeting mechanism of Angiopep-conjugated poly(ethylene glycol)-co-poly( $\varepsilon$-caprolactone) nanoparticles. Biomaterials. 2012;33(5):1673-1681.

168. Lu W, Tan YZ, Hu KL, Jiang XG. Cationic albumin conjugated pegylated nanoparticle with its transcytosis ability and little toxicity against blood-brain barrier. Int J Pharm. 2005;295(1-2): 247-260.

169. Mainardes RM, Urban MC, Cinto PO, Chaud MV, Evangelista RC, Gremião MP. Liposomes and micro/nanoparticles as colloidal carriers for nasal drug delivery. Curr Drug Deliv. 2006;3(3):275-285.

170. Mistry A, Stolnik S, Illum L. Nanoparticles for direct nose-to-brain delivery of drugs. Int J Pharm. 2009;379(1):146-157.

171. Illum L. Transport of drugs from the nasal cavity to the central nervous system. Eur J Pharm Sci. 2000;11(1):1-18.

172. Vila A, Gill H, McCallion O, Alonso MaJ. Transport of PLA-PEG particles across the nasal mucosa: effect of particle size and PEG coating density. J Control Release. 2004;98(2):231-244.
173. Rocha S. Targeted drug delivery across the blood-brain barrier in Alzheimer's disease. Curr Pharm Des. 2013;19(37):6635-6646.

174. Pawar D, Mangal S, Goswami R, Jaganathan KS. Development and characterization of surface modified PLGA nanoparticles for nasal vaccine delivery: effect of mucoadhesive coating on antigen uptake and immune adjuvant activity. Eur J Pharm Biopharm. 2013;85(3 Pt A): $550-559$

175. Sun W, Xie C, Wang H, Hu Y. Specific role of polysorbate 80 coating on the targeting of nanoparticles to the brain. Biomaterials. 2004;25(15):3065-3071.

176. Gao X, Tao W, Lu W, et al. Lectin-conjugated PEG-PLA nanoparticles: preparation and brain delivery after intranasal administration. Biomaterials. 2006;27(18):3482-3490.

177. Gutzmann H, Hadler D. Sustained efficacy and safety of idebenone in the treatment of Alzheimer's disease: update on a 2-year double-blind multicentre study. J Neural Transm Suppl. 1998;54:301-310.

178. Weyer G, Babej-Dölle RM, Hadler D, Hofmann S, Herrmann WM. A controlled study of 2 doses of idebenone in the treatment of Alzheimer's disease. Neuropsychobiology. 1997;36(2):73-82.

179. Sinha M, Bhowmick P, Banerjee A, Chakrabarti S. Antioxidant role of amyloid $\beta$ protein in cell-free and biological systems: implication for the pathogenesis of Alzheimer disease. Free Radic Biol Med. 2013;56:184-192.

180. Butterfield DA, Castegna A, Lauderback CM, Drake J. Evidence that amyloid beta-peptide-induced lipid peroxidation and its sequelae in Alzheimer's disease brain contribute to neuronal death. Neurobiol Aging. 2002;23(5):655-664.

181. Butterfield DA, Yatin SM, Varadarajan S, Koppal T. Amyloid betapeptide-associated free radical oxidative stress, neurotoxicity, and Alzheimer's disease. Methods Enzymol. 1999;309:746-768.

182. Illum L. Chitosan and its use as a pharmaceutical excipient. Pharm Res. 1998;15(9):1326-1331.

183. Smart JD. The basics and underlying mechanisms of mucoadhesion. Adv Drug Deliv Rev. 2005;57(11):1556-1568.

184. Carvalho FC, Bruschi ML, Evangelista RC, Gremião MPD. Mucoadhesive drug delivery systems. Brazilian Journal of Pharmaceutical Sciences. 2010;46:1-17.

185. Carvalho FC, Chorilli M, Gremião MPD. Plataformas bio(muco) adesivas poliméricas baseadas em nanotecnologia para liberação controlada de fármacos - propriedades, metodologias e aplicações. Polímeros. 2014;24:203-213. Portuguese.

186. Cardile V, Frasca G, Rizza L, et al. Improved adhesion to mucosal cells of water-soluble chitosan tetraalkylammonium salts. Int J Pharm. 2008;362(1-2):88-92.

187. Henriksen I, Green KL, Smart JD, Smistad G, Karlsen J. Bioadhesion of hydrated chitosans: an in vitro and in vivo study. Int J Pharm. 1996;145(1-2):231-240.

188. Bodmer M, Vankan P, Dreier M, Kutz KW, Drewe J. Pharmacokinetics and metabolism of idebenone in healthy male subjects. Eur J Clin Pharmacol. 2009;65(5):493-501.

189. Müller RH, Radtke M, Wissing SA. Solid lipid nanoparticles (SLN) and nanostructured lipid carriers (NLC) in cosmetic and dermatological preparations. Adv Drug Deliv Rev. 2002;54 Suppl 1: S131-S155.

190. Mehnert W, Mäder K. Solid lipid nanoparticles: production, characterization and applications. Adv Drug Deliv Rev. 2012;64 Suppl: 83-101.

191. Pardeike J, Hommoss A, Müller RH. Lipid nanoparticles (SLN, NLC) in cosmetic and pharmaceutical dermal products. Int J Pharm 2009;366(1-2):170-184.

192. Kovačević AB, Müller RH, Savić SD, Vuleta GM, Keck CM. Solid lipid nanoparticles (SLN) stabilized with polyhydroxy surfactants: preparation, characterization and physical stability investigation. Colloids Surf A Physicochem Eng Asp. 2014;444:15-25.

193. Lukowski G, Kasbohm J, Pflegel P, Illing A, Wulff H. Crystallographic investigation of cetylpalmitate solid lipid nanoparticles. Int J Pharm. 2000;196(2):201-205. 
194. Martins SM, Sarmento B, Nunes C, Lúcio M, Reis S, Ferreira DC. Brain targeting effect of camptothecin-loaded solid lipid nanoparticles in rat after intravenous administration. Eur J Pharm Biopharm. 2013;85(3 Pt A):488-502.

195. Xie S, Zhu L, Dong Z, et al. Preparation, characterization and pharmacokinetics of enrofloxacin-loaded solid lipid nanoparticles: influences of fatty acids. Colloids Surf B Biointerfaces. 2011;83(2):382-387.

196. Kolenyak-Santos F, Garnero C, Oliveira RN, et al. Nanostructured lipid carriers as a strategy to improve the in vitro schistosomiasis activity of praziquantel. J Nanosci Nanotechnol. 2014;14:1-12.

197. Kumar VV, Chandrasekar D, Ramakrishna S, Kishan V, Rao YM, Diwan PV. Development and evaluation of nitrendipine loaded solid lipid nanoparticles: Influence of wax and glyceride lipids on plasma pharmacokinetics. Int J Pharm. 2007;335(1-2):167-175.

198. Das S, Ng WK, Kanaujia P, Kim S, Tan RB. Formulation design, preparation and physicochemical characterizations of solid lipid nanoparticles containing a hydrophobic drug: effects of process variables. Colloids Surf B Biointerfaces. 2011;88(1):483-489.

199. Vitorino C, Carvalho FA, Almeida AJ, Sousa JJ, Pais AA. The size of solid lipid nanoparticles: an interpretation from experimental design. Colloids Surf B Biointerfaces. 2011;84(1):117-130.

200. Rahman Z, Zidan AS, Khan MA. Non-destructive methods of characterization of risperidone solid lipid nanoparticles. Eur J Pharm Biopharm. 2010;76(1):127-137.

201. Kumar R, Yasir M, Saraf SA, Gaur PK, Kumar Y, Singh AP. Glyceryl monostearate based nanoparticles of mefenamic acid: fabrication and in vitro characterization. Drug Invention Today. 2013;5(3):246-250.

202. Yasir M, Sara UVS. Preparation and optimization of haloperidol loaded solid lipid nanoparticles by Box-Behnken design. J Pharm Res. 2013;7(6):551-558.

203. Singh AP, Saraf SK, Saraf S. SLN approach for nose-to-brain delivery of alprazolam. Drug Deliv Transl Res. 2012;2(6):498-507.

204. Trotta M, Debernardi F, Caputo O. Preparation of solid lipid nanoparticles by a solvent emulsification-diffusion technique. Int J Pharm. 2003;257(1-2):153-160.

205. Campardelli R, Cherain M, Perfetti C, et al. Lipid nanoparticles production by supercritical fluid assisted emulsion-diffusion. J Supercrit Fluids. 2013;82:34-40.

206. Acevedo-Morantes CY, Acevedo-Morantes MT, Suleiman-Rosado D, Ramírez-Vick JE. Evaluation of the cytotoxic effect of camptothecin solid lipid nanoparticles on MCF7 cells. Drug Deliv. 2013;20(8):338-348.

207. de Souza ALR, Andreani T, Nunes FM, et al. Loading of praziquantel in the crystal lattice of solid lipid nanoparticles. J Therm Anal Calorim. 2012;108(1):353-360.

208. de Souza ALR, Andreani T, de Oliveira RN, et al. In vitro evaluation of permeation, toxicity and effect of praziquantel-loaded solid lipid nanoparticles against Schistosoma mansoni as a strategy to improve efficacy of the schistosomiasis treatment. Int J Pharm. 2014;463(1):31-37.

209. de Almeida AE, Souza ALR, Cassimiro DL, Gremião MPD, Ribeiro CA, Crespi MS. Thermal characterization of solid lipid nanoparticles containing praziquantel. J Therm Anal Calorim. 2012;108(1): 333-339.

210. Freitas C, Müllera RH. Spray-drying of solid lipid nanoparticles (SLN TM). Eur J Pharm Biopharm. 1998;46(2):145-151.

211. Bourezg Z, Bourgeois S, Pressenda S, Shehada T, Fessi H. Redispersible lipid nanoparticles of spironolactone obtained by three drying methods. Colloids Surf A Physicochem Eng Asp. 2012;413:191-199.

212. Chavan SS, Ingle SG, Vavia PR. Preparation and characterization of solid lipid nanoparticle-based nasal spray of budesonide. Drug Deliv Transl Res. 2013;3(5):402-408.

213. Martins S, Silva AC, Ferreira DC, Souto EB. Improving oral absorption of salmon calcitonin by trimyristin lipid nanoparticles. J Biomed Nanotechnol. 2009;5(1):76-83.

214. Dong Y, Ng WK, Shen S, Kim S, Tan RB. Solid lipid nanoparticles: continuous and potential large-scale nanoprecipitation production in static mixers. Colloids Surf B Biointerfaces. 2012;94:68-72.
215. Hombach J, Bernkop-Schnürch A. Mucoadhesive drug delivery systems. Handb Exp Pharmacol. 2010;(197):251-266.

216. Masserini M. Nanoparticles for brain drug delivery. ISRN Biochem. 2013;2013:238428.

217. Alyautdin RN, Tezikov EB, Ramge P, Kharkevich DA, Begley DJ, Kreuter J. Significant entry of tubocurarine into the brain of rats by adsorption to polysorbate 80 -coated polybutylcyanoacrylate nanoparticles: an in situ brain perfusion study. J Microencapsul. 1998;15(1):67-74

218. Gulyaev AE, Gelperina SE, Skidan IN, Antropov AS, Kivman GY, Kreuter J. Significant transport of doxorubicin into the brain with polysorbate 80-coated nanoparticles. Pharm Res. 1999;16(10): 1564-1569.

219. Kreuter J, Alyautdin RN, Kharkevich DA, Ivanov AA. Passage of peptides through the blood-brain barrier with colloidal polymer particles (nanoparticles). Brain Res. 1995;674(1):171-174.

220. Thal LJ, Salmon DP, Lasker B, Bower D, Klauber MR. The safety and lack of efficacy of vinpocetine in Alzheimer's disease. J Am Geriatr Soc. 1989;37(6):515-520.

221. Szatmari SZ, Whitehouse PJ. Vinpocetine for cognitive impairment and dementia. Cochrane Database Syst Rev. 2003;(1): CD003119.

222. Marambaud P, Vingtdeux V, Giliberto L, et al. Resveratrol lowers beta-amyloid accumulation and deposition in vivo by controlling AMPK signaling. Alzheimers Dement. 2010;6(4):S406.

223. Bondi ML, Montana G, Craparo EF, et al. Ferulic acid-loaded lipid nanostructures as drug delivery systems for Alzheimer's disease: preparation, characterization and cytotoxicity studies. Curr Nanosci. 2009;5(1):26-32.

224. Wang BS, Wang H, Wei ZH, Song YY, Zhang L, Chen HZ. Efficacy and safety of natural acetylcholinesterase inhibitor huperzine $\mathrm{A}$ in the treatment of Alzheimer's disease: an updated meta-analysis. J Neural Transm. 2009;116(4):457-465.

225. Huang HC, Chang P, Dai XL, Jiang ZF. Protective effects of curcumin on amyloid- $\beta$-induced neuronal oxidative damage. Neurochem Res. 2012;37(7):1584-1597.

226. Ono K, Hasegawa K, Naiki H, Yamada M. Curcumin has potent antiamyloidogenic effects for Alzheimer's beta-amyloid fibrils in vitro. J Neurosci Res. 2004;75(6):742-750.

227. Yang F, Lim GP, Begum AN, et al. Curcumin inhibits formation of amyloid beta oligomers and fibrils, binds plaques, and reduces amyloid in vivo. J Biol Chem. 2005;280(7):5892-5901.

228. Zhao LN, Chiu SW, Benoit J, Chew LY, Mu Y. The effect of curcumin on the stability of A $\beta$ dimers. J Phys Chem B. 2012;116(25): $7428-7435$.

229. Wang W, Zhu R, Xie Q, et al. Enhanced bioavailability and efficiency of curcumin for the treatment of asthma by its formulation in solid lipid nanoparticles. Int J Nanomedicine. 2012;7:3667-3677.

230. Sun J, Bi C, Chan HM, Sun S, Zhang Q, Zheng Y. Curcumin-loaded solid lipid nanoparticles have prolonged in vitro antitumour activity, cellular uptake and improved in vivo bioavailability. Colloids Surf B Biointerfaces. 2013;111:367-375.

231. Wang P, Zhang L, Peng H, Li Y, Xiong J, Xu Z. The formulation and delivery of curcumin with solid lipid nanoparticles for the treatment of on non-small cell lung cancer both in vitro and in vivo. Mater Sci Eng C Mater Biol Appl. 2013;33(8):4802-4808.

232. Vandita K, Shashi B, Santosh KG, Pal KI. Enhanced apoptotic effect of curcumin loaded solid lipid nanoparticles. Mol Pharm. 2012; 9(12):3411-3421.

233. Guri A, Gülseren I, Corredig M. Utilization of solid lipid nanoparticles for enhanced delivery of curcumin in cocultures of HT29-MTX and Caco-2 cells. Food Funct. 2013;4(9):1410-1419.

234. Ji H, Tang J, Li M, Ren J, Zheng N, Wu L. Curcumin-loaded solid lipid nanoparticles with Brij78 and TPGS improved in vivo oral bioavailability and in situ intestinal absorption of curcumin. Drug Deliv. Epub 2014 Jun 3:1-12. 
235. Alex A, Paul W, Chacko AJ, Sharma CP. Enhanced delivery of lopinavir to the CNS using Compritol-based solid lipid nanoparticles. Ther Deliv. 2011;2(1):25-35.

236. Kuo YC, Liang CT. Inhibition of human brain malignant glioblastoma cells using carmustine-loaded catanionic solid lipid nanoparticles with surface anti-epithelial growth factor receptor. Biomaterials. 2011;32(12):3340-3350.

237. Martins S, Tho I, Reimold I, et al. Brain delivery of camptothecin by means of solid lipid nanoparticles: formulation design, in vitro and in vivo studies. Int J Pharm. 2012;439(1-2):49-62.

238. Wang JX, Sun X, Zhang ZR. Enhanced brain targeting by synthesis of 3',5'-dioctanoyl-5-fluoro-2'-deoxyuridine and incorporation into solid lipid nanoparticles. Eur J Pharm Biopharm. 2002;54(3): $285-290$

239. Lasic DD. Novel applications of liposomes. Trends Biotechnol. 1998;16(7):307-321.

240. Gulati M, Grover M, Singh S, Singh M. Lipophilic drug derivatives in liposomes. Int J Pharm. 1998;165(2):129-168.

241. Xu X, Khan MA, Burgess DJ. Predicting hydrophilic drug encapsulation inside unilamellar liposomes. Int J Pharm. 2012;423(2): $410-418$.

242. Ghanbarzadeh S, Valizadeh H, Zakeri-Milani P. Application of response surface methodology in development of sirolimus liposomes prepared by thin film hydration technique. Bioimpacts 2013;3(2):75-81.

243. Elzainy AA, Gu X, Simons FE, Simons KJ. Hydroxyzine- and cetirizine-loaded liposomes: effect of duration of thin film hydration, freeze-thawing, and changing buffer $\mathrm{pH}$ on encapsulation and stability. Drug Dev Ind Pharm. 2005;31(3):281-291.

244. Li X, Chen D, Le C, et al. Novel mucus-penetrating liposomes as a potential oral drug delivery system: preparation, in vitro characterization, and enhanced cellular uptake. Int $J$ Nanomedicine. 2011;6:3151-3162.

245. Chorilli M, Calixto G, Rimério TC, Scarpa MV. Caffeine encapsulated in small unilamellar liposomes: characerization and in vitro release profile. J Dispers Sci Technol. 2013;34(10):1465-1470.

246. Chorilli M, Rimério TC, De Oliveira AG, Scarpa MV. Study of liposomes stability containing soy phosphatidylcholine and hydrogenated soy phosphatydylcholine adding or not cholesterol by turbidity method Latin American Journal of Pharmacy. 2007;26(1):31-37.

247. Chorilli M, Rimério TC, De Oliveira AG, Scarpa MV. Obtaining and characterization of small unilamellar liposomes containing caffeine. Latin American Journal of Pharmacy. 2007;26(5):715-722.

248. Barichello JM, Kizuki S, Tagami T, et al. Agitation during lipoplex formation harmonizes the interaction of siRNA to cationic liposomes. Int J Pharm. 2012;430(1-2):359-365.

249. Hadian Z, Sahari MA, Moghimi HR, Barzegar M. Formulation, characterization and optimization of liposomes containing eicosapentaenoic and docosahexaenoic acids; a methodology approach. Iran J Pharm Res. 2014;13(2):393-404.

250. Cho NJ, Hwang LY, Solandt JJR, Frank CW. Comparison of extruded and sonicated vesicles for planar bilayer self-assembly. Materials. 2013;6(8):3294-3308.

251. Isailović BD, Kostić IT, Zvonar A, et al. Resveratrol loaded liposomes produced by different techniques. Innovative Food Science and Emerging Technologies. 2013;19:181-189.

252. Curić A, Reul R, Möschwitzer J, Fricker G. Formulation optimization of itraconazole loaded PEGylated liposomes for parenteral administration by using design of experiments. Int J Pharm. 2013;448(1):189-197.

253. Ninomiya K, Kawabata S, Tashita H, Shimizu N. Ultrasound-mediated drug delivery using liposomes modified with a thermosensitive polymer. Ultrason Sonochem. 2014;21(1):310-316.

254. Mourão SC, Costa PI, Salgado HR, Gremião MP. Improvement of antischistosomal activity of praziquantel by incorporation into phosphatidylcholine-containing liposomes. Int J Pharm. 2005; 295(1-2):157-162.
255. Ye $\mathrm{P}$, Zhang $\mathrm{W}$, Yang $\mathrm{T}$, et al. Folate receptor-targeted liposomes enhanced the antitumor potency of imatinib through the combination of active targeting and molecular targeting. Int J Nanomedicine. 2014;9:2167-2178.

256. Olson F, Hunt CA, Szoka FC, Vail WJ, Papahadjopoulos D. Preparation of liposomes of defined size distribution by extrusion through polycarbonate membranes. Biochim Biophys Acta. 1979;557(1):9-23.

257. Jousma H, Talsma H, Spies F, Joosten JGH, Junginger HE, Crommelin DJA. Characterization of liposomes. The influence of extrusion of multilamellar vesicles through polycarbonate membranes on particle size, particle size distribution and number of bilayers. Int J Pharm. 1987;35(3):263-274

258. Berger N, Sachse A, Bender J, Schubert R, Brandl M. Filter extrusion of liposomes using different devices: comparison of liposome size, encapsulation efficiency, and process characteristics. Int J Pharm. 2001;223(1-2):55-68.

259. Pupo E, Padrón A, Santana E, et al. Preparation of plasmid DNAcontaining liposomes using a high-pressure homogenization - extrusion technique. J Control Release. 2005;104(2):379-396.

260. Barnadas-Rodriguez R, Sabés M. Factors involved in the production of liposomes with a high-pressure homogenizer. Int J Pharm. 2001; 213(1-2):175-186.

261. Brandl M, Bachmann D, Drechsler M, Bauer KH. Liposome preparation by a new high pressure homogenizer Gaulin Micron Lab 40. Drug Dev Ind Pharm. 1990;16(14):2167-2191.

262. Chung SK, Shin GH, Jung MK, Hwang IC, Park HJ. Factors influencing the physicochemical characteristics of cationic polymer-coated liposomes prepared by high-pressure homogenization. Colloids Surf A Physicochem Eng Asp. 2014;454:8-15.

263. Szoka F Jr, Papahadjopoulos D. Procedure for preparation of liposomes with large internal aqueous space and high capture by reverse-phase evaporation. Proc Natl Acad Sci U S A. 1978;75(9):4194-4198.

264. Cortesi R, Esposito E, Gambarin S, Telloli P, Menegatti E, Nastruzzi C. Preparation of liposomes by reverse-phase evaporation using alternative organic solvents. J Microencapsul. 1999;16(2):251-256.

265. Chen G, Li D, Jin Y, et al. Deformable liposomes by reverse-phase evaporation method for an enhanced skin delivery of (+)-catechin. Drug Dev Ind Pharm. 2013;40(2):260-265.

266. García-Jimeno S, Escribano E, Queralt J, Estelrich J. Magnetoliposomes prepared by reverse-phase followed by sequential extrusion: Characterization and possibilities in the treatment of inflammation. Int J Pharm. 2011;405(1-2):181-187.

267. Kaur IP, Garg A, Singla AK, Aggarwal D. Vesicular systems in ocular drug delivery: an overview. Int J Pharm. 2004;269(1):1-14

268. Malmsten M. Liposomes. In: Surfactants and Polymers in Drug Delivery. CRC Press; 2002.

269. Agarwal R, Katare OP, Vyas SP. Preparation and in vitro evaluation of liposomal/niosomal delivery systems for antipsoriatic drug dithranol. Int J Pharm. 2001;228(1-2):43-52.

270. Cevc G, Blume G. Lipid vesicles penetrate into intact skin owing to the transdermal osmotic gradients and hydration force. Biochim Biophy Acta. 1992;1104(1):226-232.

271. Arora S, Lamba HS, Tiwari R. Dermal delivery of drugs using different vesicular carriers: a comparative review. Asian Journal of Pharmaceutics. 2012;6(4):237-244.

272. Touitou E, Dayan N, Bergelson L, Godin B, Eliaz M. Ethosomes - novel vesicular carriers for enhanced delivery: characterization and skin penetration properties. J Control Release. 2000;65(3):403-418.

273. Saroj S, Baby DA, Sabitha M. Current trends in lipid based delivery systems and its applications in drug delivery. Asian Journal of Pharmaceutical and Clinical Research. 2012;5(Supp1 3):4-9.

274. Schnyder A, Huwyler J. Drug transport to brain with targeted liposomes. Neuro Rx. 2005;2(1):99-107.

275. De Rosa G, Salzano G, Caraglia M, Abbruzzese A. Nanotechnologies: a strategy to overcome blood-brain barrier. Curr Drug Metab. 2012;13(1):61-69. 
276. Loureiro JA, Gomes B, Coelho MAN, do Carmo Pereira M, Rocha S. Targeting nanoparticles across the blood-brain barrier with monoclonal antibodies. Nanomedicine (Lond). 2014;9(5):709-722.

277. Murugan K, Choonara YE, Kumar P, Bijukumar D, du Toit LC, Pillay V. Parameters and characteristics governing cellular internalization and trans-barrier trafficking of nanostructures. Int J Nanomedicine. 2015;10:2191-2206.

278. Herda LM, Polo E, Kelly PM, Rocks L, Hudecz D, Dawson KA. Designing the future of nanomedicine: current barriers to targeted brain therapeutics. Eur J Nanomed. 2014;6(3):127-139.

279. Lai F, Fadda AM, Sinico C. Liposomes for brain delivery. Expert Opin Drug Deliv. 2013;10(7):1003-1022.

280. Salvati E, Re F, Sesana S, et al. Liposomes functionalized to overcome the blood-brain barrier and to target amyloid- $\beta$ peptide: the chemical design affects the permeability across an in vitro model. Int J Nanomedicine. 2013;8:1749-1758.

281. Hashizume R, Frey WH II. Intranasal delivery - a new therapeutic approach for brain tumors. US Neurol. 2008;4(2):43-44.

282. Tayebati SK, Nwankwo IE, Amenta F. Intranasal drug delivery to the central nervous system: present status and future outlook. Curr Pharm Des. 2013;19(3):510-526.

283. Shah L, Yadav S, Amiji M. Nanotechnology for CNS delivery of biotherapeutic agents. Drug Deliv Transl Res. 2013;3(4):336-351.

284. Malouf R, Grimley Evans J. Folic acid with or without vitamin B12 for the prevention and treatment of healthy elderly and demented people. Cochrane Database Syst Rev. 2008;(4):CD004514.

285. Birks J, Grimley Evans J. Ginkgo biloba for cognitive impairment and dementia. Cochrane Database Syst Rev. 2009;(1):CD003120.

286. Ezrahi S, Aserin A, Garti N. Aggregation behavior in one-phase (Winsor IV) microemulsion systems. In: Kumar P, Mittal KL, editors. Handbook of Microemulsion Science and Technology. New York: Marcel Dekker, Inc; 1999:195-240.

287. Malmsten M. Surfactants and Polymers in Drug Delivery. New York: CRC Press; 2002.

288. Langevin D. Microemulsions. Acc Chem Res. 1988;21(7):255-260.

289. Manoharan C, Basarkar A, Singh J. Various pharmaceutical disperse systems. In: Kulshreshtha AK, Singh ON, Wall GM, editors. Pharmaceutical Suspensions: From Formulation Development to Manufacturing. New York: Springer; 2010:1-37.

290. McClements DJ. Nanoemulsions versus microemulsions: terminology, differences, and similarities. Soft Matter. 2012;8(6):1719-1729.

291. Mason TG, Wilking JN, Meleson K, Chang CB, Graves SM. Nanoemulsions: formation, structure, and physical properties. J Phys Condens Matter. 2006;18:R635.

292. Urban MCC, Mainardes RM, Gremião MPD. Development and validation of HPLC method for analysis of dexamethasone acetate in microemulsions. Brazilian Journal of Pharmaceutical Sciences. 2009;45:87-92.

293. Carvalho FC, Barbi MdS, Gremião MPD. LC evaluation of in vitro release of AZT from microemulsions. Chromatographia. 2009; 69(2):207-211.

294. Carvalho FC, Sarmento VH, Chiavacci LA, Barbi MS, Gremião MP. Development and in vitro evaluation of surfactant systems for controlled release of zidovudine. J Pharm Sci. 2010;99(5):2367-2374.

295. Macedo AS, Quelhas S, Silva AM, Souto EB. Nanoemulsions for delivery of flavonoids: formulation and in vitro release of rutin as model drug. Pharm Dev Technol. 2014;19(6):677-680.

296. Dias DdO, Colombo M, Kelmann RG, et al. Optimization of Copaiba oil-based nanoemulsions obtained by different preparation methods. Ind Crops Prod. 2014;59:154-162.

297. Lee L, Hancocks R, Noble I, Norton IT. Production of water-in-oil nanoemulsions using high pressure homogenisation: a study on droplet break-up. J Food Eng. 2014;131:33-37.

298. Jo YJ, Kwon YJ. Characterization of $\beta$-carotene nanoemulsions prepared by microfluidization technique. Food Sci Biotechnol. 2014; 23(1):107-113.
299. da Silva GB, Scarpa MV, Rossanezi G, do Egito ES, de Oliveira AG. Development and characterization of biocompatible isotropic and anisotropic oil-in-water colloidal dispersions as a new delivery system for methyl dihydrojasmonate antitumor drug. Int J Nanomedicine. 2014;9:867-876.

300. Sood S, Jain K, Gowthamarajan K. Delivery of neuroprotective polyphenol to the brain via an intranasal route for management of Alzheimer's disease. Alzheimers Dement. 2013;9(4):P299.

301. Shi J, Cong W, Wang Y, Liu Q, Luo G. Microemulsion-based patch for transdermal delivery of huperzine A and ligustrazine phosphate in treatment of Alzheimer's disease. Drug Dev Ind Pharm. 2012;38(6):752-761.

302. Malmsten M. Liquid crystals. In: Surfactants and Polymers in Drug Delivery. CRC Press; 2002.

303. Kato T, editor. Liquid Crystalline Functional Assemblies and Their Supramolecular Structures. New York: Springer; 2008.

304. Mueller-Goymann CC, Frank SG. Interaction of lidocaine and lidocaine- $\mathrm{HCl}$ with the liquid crystal structure of topical preparations. Int J Pharm. 1986;29(2-3):147-159.

305. Malmsten M. Phase transformations in self-assembly systems for drug delivery applications. J Dispers Sci Technol. 2007;28(1):63-72.

306. Garti N, Libster D, Aserin A. Lipid polymorphism in lyotropic liquid crystals for triggered release of bioactives. Food Funct. 2012; 3(7):700-713.

307. Kaasgaard T, Drummond CJ. Ordered 2-D and 3-D nanostructured amphiphile self-assembly materials stable in excess solvent. Phys Chem Chem Phys. 2006;8(43):4957-4975.

308. Drummond CJ, Fong C. Surfactant self-assembly objects as novel drug delivery vehicles. Curr Opin Colloid Interface Sci. 1999;4(6): 449-456.

309. Yaghmur A, Glatter O. Characterization and potential applications of nanostructured aqueous dispersions. Adv Colloid Interface Sci. 2009;147-148:333-342.

310. Carvalho FC, Campos ML, Peccinini RG, Gremião MPD. Nasal administration of liquid crystal precursor mucoadhesive vehicle as an alternative antiretroviral therapy. Eur J Pharm Biopharm. 2013;84(1):219-227.

311. Carvalho FC, Barbi MS, Sarmento VH, Chiavacci LA, Netto FM, Gremião MP. Surfactant systems for nasal zidovudine delivery: structural, rheological and mucoadhesive properties. J Pharm Pharmacol. 2010;62(4):430-439.

312. Shah JC, Sadhale Y, Chilukuri DM. Cubic phase gels as drug delivery systems. Adv Drug Deliv Rev. 2001;47(2-3):229-250.

313. Nielsen LS, Schubert L, Hansen J. Bioadhesive drug delivery systems. I. Characterisation of mucoadhesive properties of systems based on glyceryl mono-oleate and glyceryl monolinoleate. Eur J Pharm Sci. 1998;6(3):231-239.

314. Bruschi ML, de Freitas O, Lara EH, Panzeri H, Gremião MP, Jones DS. Precursor system of liquid crystalline phase containing propolis microparticles for the treatment of periodontal disease: development and characterization. Drug Dev Ind Pharm. 2008;34(3): 267-278.

315. Spicer PT, Small WB II, Small WB, Lynch ML, Burns JL. Dry powder precursors of cubic liquid crystalline nanoparticles (cubosomes). J Nanopart Res. 2002;4(4):297-311.

316. Ren X, Svirskis D, Alany RG, Zargar-Shoshtari S, Wu Z. In-situ phase transition from microemulsion to liquid crystal with the potential of prolonged parenteral drug delivery. Int J Pharm. 2012;431(1-2): 130-137.

317. Chan J, Maghraby GM, Craig JP, Alany RG. Phase transition waterin-oil microemulsions as ocular drug delivery systems: in vitro and in vivo evaluation. Int J Pharm. 2007;328(1):65-71.

318. Ahmad MZ, Ahmad J, Amin S, et al. Role of nanomedicines in delivery of anti-acetylcholinesterase compounds to the brain in Alzheimer's disease. CNS Neurol Disord Drug Targets. 2014;13(8): 1315-1324. 
319. Kumar N, Kumar R, editors. Nanomedicine for neurological disorders. In: Nanotechnology and Nanomaterials in the Treatment of Life-Threatening Diseases. Oxford: William Andrew Publishing; 2014:109-175.

320. Miyake MM, Bleier BS. The blood--brain barrier and nasal drug delivery to the central nervous system. Am J Rhinol Allergy. 2015;29(2): 124-127.

321. Wong YC, Zuo Z. Intranasal delivery - modification of drug metabolism and brain disposition. Pharm Res. 2010;27(7):1208-1223.

322. Ligade PC, Jadhav KR, Kadam VJ. Brain drug delivery system: an overview. Curr Drug ther. 2010;5(2):105-110.

323. Pathan SA, Iqbal Z, Zaidi SM, et al. CNS drug delivery systems: novel approaches. Recent Pat Drug Deliv Formul. 2009;3(1):71-89.

324. Mittal D, Ali A, Md S, Baboota S, Sahni JK, Ali J. Insights into direct nose to brain delivery: current status and future perspective. Drug Deliv. 2014;21(2):75-86.

325. Kozlovskaya L, Abou-Kaoud M, Stepensky D. Quantitative analysis of drug delivery to the brain via nasal route. J Control Release. 2014;189:133-140.

326. Alam MI, Beg S, Samad A, et al. Strategy for effective brain drug delivery. Eur J Pharm Sci. 2010;40(5):385-403.
327. Lajoie JM, Shusta EV. Targeting receptor-mediated transport for delivery of biologics across the blood-brain barrier. Annu Rev Pharmacol Toxicol. 2015;55:613-631.

328. Gaillard PJ, Visser CC, Appeldoorn CC, Rip J. Targeted blood-to-brain drug deliver - 10 key development criteria. Curr Pharm Biotechnol. 2012;13(12):2328-2339.

329. Kozlovskaya L, Stepensky D. Quantitative analysis of the braintargeted delivery of drugs and model compounds using nano-delivery systems. J Control Release. 2013;171(1):17-23.

330. Gulati M, Chopra DS, Singh SK, Saluja V, Pathak P, Bansal P. Patents on brain permeable nanoparticles. Recent Pat CNS Drug Discov. 2013;8(3):220-234.

331. Spuch C, Saida O, Navarro C. Advances in the treatment of neurodegenerative disorders employing nanoparticles. Recent Pat Drug Deliv Formul. 2012;6(1):2-18.

332. Fan AM, Alexeeff G. Nanotechnology and nanomaterials: toxicology, risk assessment, and regulations. J Nanosci Nanotechnol. 2010;10(12):8646-8657.
International Journal of Nanomedicine

\section{Publish your work in this journal}

The International Journal of Nanomedicine is an international, peerreviewed journal focusing on the application of nanotechnology in diagnostics, therapeutics, and drug delivery systems throughout the biomedical field. This journal is indexed on PubMed Central, MedLine, CAS, SciSearch $®$, Current Contents $\AA /$ Clinical Medicine,

\section{Dovepress}

Journal Citation Reports/Science Edition, EMBase, Scopus and the Elsevier Bibliographic databases. The manuscript management system is completely online and includes a very quick and fair peer-review system, which is all easy to use. Visit http://www.dovepress.com/ testimonials.php to read real quotes from published authors. 